\title{
Reviewing PSA-Based Analyses to Modify Technical Specifications at Nuclear Power Plants
}

\author{
RECEIVED \\ JAN $O 81996$ \\ OSTI
}

Prepared by

P. K. Samanta, G. Martinez-Guridi, W. E. Vesely

Brookhaven National Laboratory

Prepared for

U.S. Nuclear Regulatory Commission

\section{MASTER}

DISTRIBUTION OF THIS DOCIMENT IS UNLMMTED 


\section{AVAILABILITY NOTICE}

Availability of Reference Materials Cited in NRC Publications

Most documents cited in NRC publications will be available from one of the following sources:

1. The NRC Public Document Room, 2120 L Street, NW., Lower Level, Washington, DC 20555-0001

2. The Superintendent of Documents, U.S. Government Printing Office, P. O. Box 37082 , Washington, DC 20402-9328

3. The National Technical Information Service, Springfield, VA 22161-0002

Although the listing that follows represents the majority of documents cited in NRC publications, it is not intended to be exhaustive.

Referenced documents available for inspection and copying for a fee from the NRC Public Document Room include NRC correspondence and internal NRC memoranda; NRC bulletins, circulars, information notices, inspection and investigation notices; licensee event reports; vendor reports and correspondence; Commission papers; and applicant and licensee documents and correspondence.

The following documents in the NUREG series are available for purchase from the Government Printing Office: formal NRC staff and contractor reports, NRC-sponsored conference proceedings, international agreement reports, grantee reports, and NRC booklets and brochures. Also available are regulatory guides, NRC regulations in the Code of Federal Regulations, and Nuclear Regulatory Commission Issuances.

Documents avallable from the National Technical Information Service include NUREG-series reports and technical reports prepared by other Federal agencies and reports prepared by the Atomic Energy Commission, forerunner agency to the Nuclear Regulatory Commission.

Documents available from public and special technical libraries include all open literature items, such as books. journal articles, and transactions. Federal Register notices. Federal and State legislation, and congressional reports can usually be obtained from these libraries.

Documents such as theses, dissertations, foreign reports and translations, and non-NRC conference proceedings are available for purchase from the organization sponsoring the publication cited.

Single copies of NRC draft reports are available free. to the extent of supply, upon written request to the Office of Administration, Distribution and Mail Services Section, U.S. Nuclear Regulatory Commission. Washington, DC 20555-0001.

Copies of industry codes and standards used in a substantive manner in the NRC regulatory process are maintained at the NRC Library. Two White Flint North, 11545 Rockville Pike. Rockville, MD 20852-2738, for use by the public. Codes and standards are usually copyrighted and may be purchased from the originating organization or, if they are American National Standards, from the American National Standards Institute, 1430 Broadway, New York, NY 10018-3308.

\section{DISCLAIMER NOTICE}

This report was prepared as an account of work sponsored by an agency of the United States Government. Neither the United States Government nor any agency thereof, nor any of their employees, makes any warranty, expressed or implied, or assumes any legal liability or responsibility for any third party's use, or the results of such use, of any information, apparatus, product, or process disclosed in this report, or represents that its use by such third party would not infringe privately owned rights. 
NUREG/CR-6172

BNL-NUREG-52428

\section{Reviewing PSA-Based Analyses to Modify Technical Specifications at Nuclear Power Plants}

Manuscript Completed: October 1995

Date Published: December 1995

Prepared by

P. K. Samanta, G. Martinez-Guridi, W. E. Vesely*

Brookhaven National Laboratory

Upton, NY 11973-5000

E. Chelliah, NRC Project Manager

Prepared for

Division of Systems Technology

Office of Nuclear Regulatory Research

U.S. Nuclear Regulatory Commission

Washington, DC 20555-0001

NRC Job Code L2591

*Science Applications International Corporation

655 Metro Place South

Suite 745

Dublin, $\mathrm{OH} 43017$ 


\section{DISCLAIMER}

This report was prepared as an account of work sponsored by an agency of the United States Government. Neither the United States Government nor any agency thereof, nor any of their employees, make any warranty, express or implied, or assumes any legal liabilty or responsibility for the accuracy, completeness, or usefulness of any information, apparatus, product, or process disclosed, or represents that its use would not infringe privately owned rights. Reference herein to any specific commercial product, process, or service by trade name, trademark, manufacturer, or otherwise does not necessarily constitute or imply its endorsement, recommendation, or favoring by the United States Government or any agency thereof. The views and opinions of authors expressed herein do not necessarily state or reflect those of the United States Government or any agency thereof. 


\section{DISCLAMMER}

Portions of this document may be illegible in electronic image products. Images are produced from the best available original document. 


\begin{abstract}
Changes to Technical Specifications (TSs) at nuclear power plants (NPPs) require review and approval by the United States Nuclear Regulatory Commission (USNRC). Currently, many requests for changes to TSs use analyses that are based on a plant's probabilistic safety assessment (PSA). This report presents an approach to reviewing such PSA-based submittals for changes to TSs.

We discuss the basic objectives of reviewing a PSA-based submittal to modify NPP TSs; the methodology of reviewing a TS submittal, and the differing roles of a PSA review, a PSA Computer Code review, and a review of a TS submittal. To illustrate this approach, we discuss our review of changes to allowed outage time (AOT) and surveillance test interval (STI) in the TS for the South Texas Project Nuclear Generating Station. Based on this experience gained, a check-list of items is given for future reviewers; it can be used to verify that the submittal contains sufficient information, and also that the review has addressed the relevant issues. Finally, recommended steps in the review process and the expected findings of each step are discussed.
\end{abstract}





\section{CONTENTS}

Page

ABSTRACT $\ldots \ldots \ldots \ldots \ldots \ldots \ldots \ldots \ldots \ldots \ldots \ldots \ldots \ldots \ldots \ldots \ldots \ldots \ldots \ldots$

LIST OF TABLES $\ldots \ldots \ldots \ldots \ldots \ldots \ldots \ldots \ldots \ldots \ldots \ldots \ldots \ldots$ vii

EXECUTIVE SUMMARY $\ldots \ldots \ldots \ldots \ldots \ldots \ldots \ldots \ldots \ldots \ldots \ldots \ldots \ldots$ ix

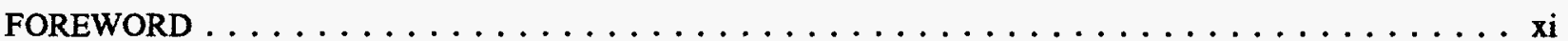

ACKNOWLEDGEMENTS $\ldots \ldots \ldots \ldots \ldots \ldots \ldots \ldots \ldots \ldots \ldots \ldots \ldots \ldots \ldots \ldots \ldots$

ABBREVIATIONS $\ldots \ldots \ldots \ldots \ldots \ldots \ldots \ldots \ldots \ldots \ldots \ldots \ldots \ldots \ldots \ldots \ldots \ldots$

1. INTRODUCTION $\ldots \ldots \ldots \ldots \ldots \ldots \ldots \ldots \ldots \ldots \ldots \ldots \ldots \ldots \ldots \ldots \ldots$

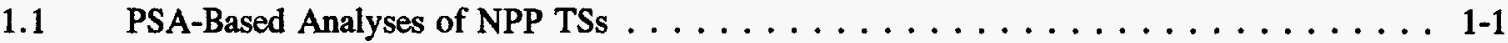

1.2 Focus and Scope of PSA-Based TS Submittals $\ldots \ldots \ldots \ldots \ldots \ldots \ldots \ldots \ldots \ldots$

1.3 Objectives of the Review . . . . . . . . . . . . . . . . . . . 1-2

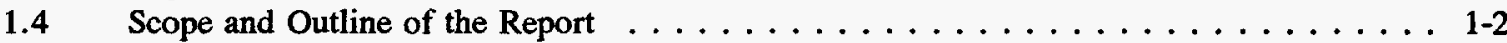

2. PLANT PSA, PSA-BASED TS ANALYSIS, AND REVIEW $\ldots \ldots \ldots \ldots \ldots \ldots \ldots \ldots$

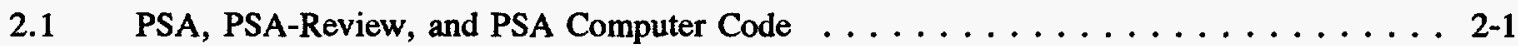

2.2 Review of the PSA for TS Applications . . . . . . . . . . . . . . 2-2

3. METHODOLOGY OF THE REVIEW $\ldots \ldots \ldots \ldots \ldots \ldots \ldots \ldots \ldots \ldots \ldots \ldots \ldots$

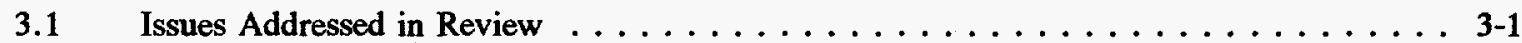

3.2 Reason for Requesting Modification . . . . . . . . . . . . . . . 3-1

3.3 Applicable Risk Measures for AOT and STI Modification . . . . . . . . . . 3-2

3.4 Modeling of TS Parameters $\ldots \ldots \ldots \ldots \ldots \ldots \ldots \ldots \ldots \ldots \ldots \ldots \ldots$

3.5 Data Used in Support of Analysis . . . . . . . . . . . . . . . . . . 3-5

3.6 Check on Quantification Performed . . . . . . . . . . . . . . . 3-6

3.7 Sensitivity and Uncertainty Analysis $\ldots \ldots \ldots \ldots \ldots \ldots \ldots \ldots \ldots \ldots \ldots \ldots \ldots$

3.8 Strategy Used to Define the Requested TS Change . . . . . . . . . . . . . 3-7

3.9 Presentation of Results $\ldots \ldots \ldots \ldots \ldots \ldots \ldots \ldots \ldots \ldots \ldots \ldots$. . . . . . . . . . .

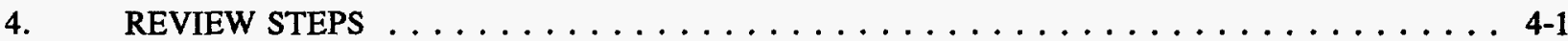

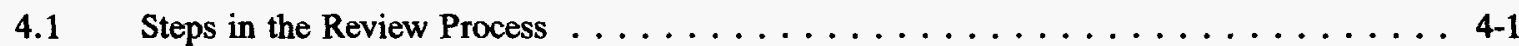

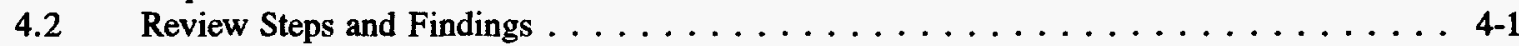

5. CHECK-LIST OF ITEMS FOR REVIEWING PSA-BASED TS SUBMITTAL $\ldots \ldots \ldots$

5.1 Check-List of Items for Review . . . . . . . . . . . . . . . . 5-1

5.2 Check-List 1: Type and Justification of the Requested TS Changes . . . . . . . . . 5-1

5.3 Check-List 2: Qualitative Review of Risk-Based TS (AOT/STI) Submittal . . . . . . 5-3

5.4 Check-List 3: Detailed Review of Risk-Based TS Submittal $\ldots \ldots \ldots \ldots \ldots \ldots$ 5-10 
CONTENTS (Cont'd.)

$\underline{\text { Page }}$

6. EXAMPLE OF A REVIEW OF A PSA-BASED TS SUBMITTAL $\ldots \ldots \ldots \ldots \ldots$

6.1 STP PSA-Based TS Submittal, STP PSA, and Review of STP PSA $\ldots \ldots \ldots \ldots \ldots$ 6-1

6.2 Proposed TS Changes for STP Stations . . . . . . . . . . . . . . . 6-2

6.3 Scope of the Review Technical Specification Modifications . . . . . . . . . . . 6-2

6.4 Overview of the Review Steps and the Findings . . . . . . . . . . . . . . . 6-4

6.5 Review of STP Methodology for Proposed TS Modifications . . . . . . . . . . . 6-5

6.5.1 Assessment of the STP Methodology Used to Calculate the

AOT Risk Contributions . . . . . . . . . . . . . . . . . . 6-5

6.5.2 Assessment of the STP Methodology Used to Calculate STI

Risk Contributions $\ldots \ldots \ldots \ldots \ldots \ldots \ldots \ldots \ldots \ldots \ldots \ldots$ 6 $6 \ldots \ldots \ldots$

6.6 General Observations Regarding STP Submittal Impacting Review

of the Requested TS Changes $\ldots \ldots \ldots \ldots \ldots \ldots \ldots \ldots \ldots$. . . . . . . . . . . . . .

6.7 Analysis of Requested Technical Specification Changes $\ldots \ldots \ldots \ldots \ldots \ldots$. . . 6-9

6.7.1 Categorization of Proposed Changes in STP Submittal Based on the Impact on Average Plant CDF . . . . . . . . . . . . . . . . 6-9

6.7 .2 Analysis of TS Changes with Negligible CDF Impacts $\ldots \ldots \ldots \ldots \ldots \ldots .6$ 6-11

6.7.3 Analysis of TS Changes with Non-Negligible Impact on Average Plant CDF . . . . . . . . . . . . . . . . . . . 6 6-13

6.7.4 Analyses of TS Changes Involving Containment Systems . . . . . . . . 6-14

6.8 Technical Review Conclusion $\ldots \ldots \ldots \ldots \ldots \ldots \ldots \ldots \ldots \ldots \ldots \ldots$ 6-14

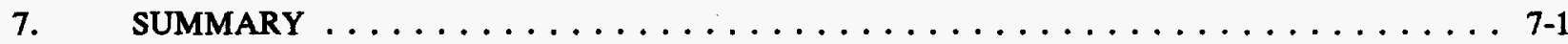

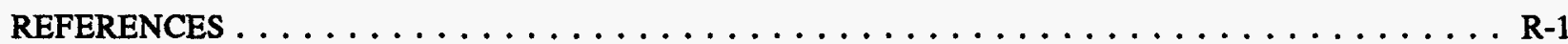




\section{LIST OF TABLES}

Page

5.1 List of Items to Determine the Type and Reasonableness of the Requested TS Changes . . . . . 5-2

5.2 Check-List for Review of a Risk-Based TS (AOT/STI) Submittal $\ldots \ldots \ldots \ldots \ldots \ldots \ldots$

5.3 Check-List for Use During the Detailed Review $\ldots \ldots \ldots \ldots \ldots \ldots \ldots \ldots \ldots \ldots$

6.1 Proposed Modifications to the South Texas Project Technical Specifications . . . . . . . . 6-3

6.2 Summary of the Risk Increases Due to the Proposed AOT and STI Increases . . . . . . . 6-8

6.3 Category 1 Proposed TS Extensions Which Result in Zero to Near Zero CDF Increases . . . . 6-10

6.4 Category 2 Proposed TS Extensions Resulting in CDF Increases not Necessarily Negligible . . 6-11

6.5 Category 3 Proposed TS Extensions Involving Containment Systems $\ldots \ldots \ldots \ldots \ldots \ldots$

6.6 Summary of the Technical Review Conclusions for Proposed Changes to the STP TSs . . . . . 6-15 



\section{EXECUTIVE SUMMARY}

This report presents an approach to reviewing probabilistic safety assessment (PSA)-based analyses of changes to the Technical Specifications (TSs) of nuclear power plants (NPPs). TSs are defined as part of the operating license of a NPP, and operation of the plant may reveal difficulties with specific aspects of the TS where changes may be desirable. Using the PSA of a plant, changes in the TS are analyzed and the justifications for the modifications are considered. The United States Nuclear Regulatory Commission (NRC) reviews and approves any modification to a plant's TS. The review of these PSA-based submittals for changes in the TS requires that relevant safety issues arising from the proposed modifications are addressed. Using as an example a review that we conducted recently, we discuss the review of such submittals.

The PSA-based submittal for changes to TS focusses on the limiting conditions for operation (LCOs) and Surveillance Requirements (SRs). The allowed outage time (AOT) within an LCO, surveillance test intervals (STIs), and surveillance test strategies (i.e., scheduling of a test in relation to the test of a redundant component) within an SR are considered. Accordingly, this report addresses the review of changes to these aspects of the TS.

We address the following aspects of a review of a PSA-based TS submittal:

a) the objectives of such a review, and the differences from a PSA review,

b) the methodology for reviewing a PSA-based TS submittal,

c) the review steps to be followed, and

d) the check-list of items for the reviewers.

We discuss our review of changes to the AOT and STI requirements at the South Texas Nuclear Generating Station to illustrate the approach. The lessons that we learnt from it were used to define the check-list of the items and the steps in the review.

The review of a PSA-based submittal of TS changes is closely related to the plant's PSA, the PSA-computer code used, and the review of the PSA. However, the reviews of the latter two are not considered the responsibility of those concerned with the PSA-based TS submittal; only those specific aspects that relate to the TS requirements are to be considered.

The methodology discusses the specific issues that must be addressed in reviewing a PSA-based TS submittal:

- Reasons for requesting the modifications to the TS,

- Calculation of applicable risk measures in quantifying the risk effects of such modifications,

- Adequacy of modeling the TS parameters in the risk model used to quantify the effects,

- Data used to support the analysis,

- Accuracy of the quantifications,

- Adequacy of the sensitivity and uncertainty analyses and their use to justify TS modifications,

- Strategy used to define the requested TS change,

- Presentation of results with sufficient details to allow their reconstruction. 
Based on this methodology, a check-list of items is provided for potential reviewers. This check-list can be used to determine early whether a submittal includes adequate analyses and information for considering the requested changes. A check-list for detailed review of a submittal is also included to assure that the relevant issues were addressed.

Finally, we discuss the steps to be followed in such a review. The steps are defined in such a way that it can be determined quickly whether the submittal is inadequate, or the requested changes are beyond those acceptable. Also, following these steps will effectively use the time and resources available to a review team. The scope of the review to be conducted in each step and the findings for each stage (which define the level of evaluations within the step) also are considered. 


\section{FOREWORD}

In response to requests from the Office of Nuclear Reactor Regulation, the NRC's Office of Nuclear Regulatory Research performed a safety evaluation of a request from Houston Lighting and Power Company (HL\&P) to modify the Technical Specifications included in the license for its South Texas plant. The justification submitted by HL\&P for this set of changes was based, in part, on probabilistic arguments. HL\&P had made use of probabilistic calculations to identify about 22 changes in the technical specifications which would increase operational convenience without causing a significant change in the overall safety profile of the plant.

The staff and its contractors had previously completed a review of a complete Probabilistic Safety Analys is (PSA) performed by HL\&P for the South Texas Plant and issued an SER on the overall facility risk. This review is documented in NUREG/CR-5606, "A Review of the South Texas Project Probabilistic Safety Analysis: Accident Frequency Estimates and Containment Binning," June 1991. The probabilistic calculations supporting HL\&P's technical specification change request were based on this PSA.

Accordingly, the Probabilistic Risk Analysis Branch, assisted by Brookhaven National Laboratory, conducted a review of the licensee's submittal. The result of the review was a Safety Evaluation Report (SER), written by the NRC staff, which was in turn based on a Technical Evaluation Report (TER), written by Brookhaven National Laboratory.

As part of its technical evaluation of the Ticensee submittal, BNL developed a simplified procedure to evaluate the proposed technical specification changes. This procedure was based on previous evaluations documented in NUREG/CR-5425, "Evaluation of Allowed Outage Times (AOTs) from a Risk and Reliability Standpoint," August 1989; NUREG/CR-5641, "A Study of Operational Risk-Based Configuration Contro1," August 1991; and NUREG/CR-5775, "Quantitative Evaluation of Surveillance Test Intervals Including Test-Caused Risks," December 1991.

This report (NUREG/CR-6172) describes the detailed technical specification review and evaluation procedure which was used to generate the TER, including the various steps used in the evaluation and the associated review checklists. These checklists include the types of proposed changes, the justification used for various types of changes, the questions asked in the review, and a 1 ist of the minimum documentation needed to complete the technical review.

A separate report summarizing the methods developed for analyzing changes in facility technical specifications that are amenable to risk analysis (i.e., estimating the impact of these changes on core damage frequency) has previously been published as NUREG/CR-6141, "Handbook of Methods for Risk-Based Analyses of Technical Specifications," December 1994 . These two reports provide complementary information on technical specification evaluations. The handbook summarizes analysis methods and equations; this procedural report describes a technical evaluation procedure for approval of proposed technical specification changes.

This report does not constitute NRC-approved regulatory requirements or guidance for evaluating current technical specification provisions. However, the reports do summarize information learned from research and actual case evaluations. 



\section{ACKNOWLEDGEMENTS}

This report was based on the experiences gained during the authors' technical evaluation of the South Texas Project (STP) submittal requesting modifications to the Technical Specifications (TS) of the STP Nuclear Generating Facility. We thank all those involved during both phases of the study. Specifically, we thank Erul Chelliah, Mark Cunningham, Christopher Grimes, Mark Reinhart, and Millard Wohl of the U.S. Nuclear Regulatory Commission (NRC) for many useful discussions, technical support during the project, and review of the report. In addition, Carl Johnson, Jr., and James Wing of NRC provided valuable review comments which improved the report. Rick Grantom and Richard Murphy of the South Texas Project (STP) staff, and Andy Dykes, Michael Emerson, Karl Fleming, Wei Tee Loh, and Donald Wakefield of PLG, Inc. were cooperative in responding to our requests for information during the technical evaluation of the STP submittal. We also thank our colleagues Adele DiBiasio, Robert Hall, James Higgins, and Inn Kim for their valuable comments.

Finally, we acknowledge Donna Storan for an excellent job in preparing this report. 



\section{ABBREVIATIONS}

ACC

AOT

CCF

$\mathrm{CCW}$

$\mathrm{CDF}$

CS

CVCS

ECC

ECW

ESFAS

HL\&P

HVAC

LERF

PSA

RCFC

RHR

RPS

STI

STP

TS
Accumulators

Allowed Outage Time

Common Cause Failure

Component Cooling Water

Core-Damage Frequency

Containment Spray

Chemical and Volume Control System

Emergency Core Cooling

Essential Chilled Water

Engineered Safeguard Features Actuation System

Houston Lighting and Power

Heating, Ventilation and Air-Conditioning

Large Early Release Frequency

Probabilistic Safety Assessment

Reactor Containment Fan Cooler

Residual Heat Removal

Reactor Protection System

Surveillance Test Interval

South Texas Project

Technical Specification 


\section{INTRODUCTION}

\subsection{PSA-Based Analyses of NPP TSs}

The Technical Specifications (TSs) of nuclear power plants (NPPs) define the limits and conditions for operation to assure safety during all phases of plant operation (NRC regulation, 10 CFR 50.36 "Technical Specification"). These specifications are part of the licensing basis for the plant, and are strictly followed.

The requirements in the TS were based originally on deterministic analyses and engineering judgments as to the margin of conservatism necessary. As operating experience accumulates, changes to these requirements may become desirable. However, these changes should be justified and require the approval of the Unites States Nuclear Regulatory Commission (USNRC).

With the availability of plant-specific probabilistic safety assessments (PSAs), many aspects of the TS can be analyzed quantitatively using the principles of risk and reliability analyses. These PSA-based evaluations form one important input in justifying the bases for the TS change. There is a growing interest in improving these requirements, using the PSA for the plant. These types of analyses are termed "Risk-Based TS Analyses" or "PSAbased TS Analyses." Over the years, USNRC has received and approved several such submittals requesting relaxation of the TS requirements; commonly, they are referred to as "Risk-Based TS Submittals."

The following are the reasons for the increasing use of PSAs to analyze and justify TS requirements:

1. PSAs quantitatively assess the impact of the changes on the plant's risk, and so the justification for the change can be based on objective arguments,

2. Blending the considerations involved in defining a TS change becomes easier, i.e., using engineering analyses, assessing operating experience, consistently applying regulatory requirements, and assessing the risk impact of the change,

3. Changes to many requirements can be assessed consistently (using risk measures), so assuring that the necessary margin of safety is maintained, and

4. A defensible basis is obtained for regulatory review.

\subsection{Focus and Scope of PSA-Based TS Submittals}

The Technical Specifications cover five areas:

a) Safety limits and limiting safety-system settings,

b) Limiting Conditions for Operation (LCOs)

c) Surveillance Requirements (SRs)

d) Design Features

e) Administrative Controls

The risk-based or PSA-based TS submittals usually address two of these five areas: LCOs and SRs. Certain aspects of the remaining areas also can be considered using a PSA, but, so far have not been the focus of the analyses.

LCOs cover the allowed outage times (AOTs) or completion times (CTs) (Standard Technical Specifications now use the term completion time) for different conditions (inoperability) of components in the safety systems, and the required actions. The required actions sometimes are referred to as "action statements." SRs include the 
surveillances to be performed, the frequency of the surveillances or the surveillance test intervals (STIs), and any requirement for scheduling tests or a test strategy.

In the past, risk-based TS submittals typically have involved relaxing the requirements, i.e., extending the AOT or the STI, involving multiple TS items. In general, for these aspects of the TS, the submittal may include relaxations, or a combination of relaxation and tightening, including multiple aspects of multiple TS items. For example, a submittal may request extending AOTs and STIs for multiple safety systems, or it may be a combination of extending and tightening where the extension of a large number of AOTs and STIs is balanced by tightening of a smaller group of them. At times, the requested change may include performing an additional test or using a specific test strategy in the TS.

\subsection{Objectives of the Review}

Any changes to the TS requested should be reviewed and found acceptable by the regulatory authority, i.e., USNRC. A risk-based TS submittal includes a detailed quantitative evaluation of the issues arising from the requested changes which are reviewed for their adequacy and acceptability for a regulatory decision. The review process may involve NRC staff and/or contractors. In this report, we discuss the technical aspects of the review of PSA-based TS submittals.

For this review, the following are technically evaluated:

a) the analyses that support the requested changes, and the assumptions used,

b) the adequacy of the treatment of issues arising from the requested changes,

c) the validity of the quantitative assessment,

d) the criteria used to define the requested changes, and

e) the acceptability of the changes.

\subsection{Scope and Outline of the Report}

The scope of this report is to define the review of a PSA-based TS submittal. To meet that objective, this report complements the "Handbook of Methods for Risk-Based Analyses of Technical Specification, NUREG/CR6141, " which defines the methods and principles for conducting risk-based analyses of different aspects of technical specifications. The handbook gives details of the methodology, steps in applying the methodology, and examples of evaluations. It is a useful reference for reviewers, but does not delineate the objectives, approach, and the steps in the review process. Thus, the handbook was an essential document for us in preparing this report, as it is for the utility conducting the analyses, and the reviewers. To avoid any overlap and for brevity, the methods for analyzing the risk impact of TS requirements are not discussed here; only specific aspects are referred to identify the methodology and state their use during the review.

Thus, the scope of this report is to address the objectives of a review, to contrast the review of a PSA with that of a risk-based or PSA-based TS submittal, to define the issues to be addressed, and to describe the methodology of the review. A check-list of items for reviewing a PSA-based TS submittal is given, and the steps in the process are discussed. 


\section{INTRODUCTION}

The review of a PSA-based submittal covers LCOs and SRs and the types of changes in those requirements. However, the general approach taken is applicable to other types of TS changes, although the specific issues to be analyzed may differ. 


\section{PLANT PSA, PSA-BASED TS ANALYSIS, AND REVIEW}

In reviewing a PSA-based TS analysis, the following documents may be available:

1. The PSA for the plant,

2. A completed review of the PSA,

3. The computer code used for the PSA and its documentation, and

4. The PSA-Based TS Analysis submitted to justify TS changes.

The PSA for the plant, Item 1, is expected to be the one completed under the Individual Plant Examination (IPE) program. A facility-specific IPE Safety Evaluation Report (SER), issued by the NRC's staff, also should be available. Item 2 includes this facility-specific IPE SER, and the resolution findings of the generic issues applicable to the utility. It also may include a detailed review of the PSA. The PSA computer code, Item 3 , may be a standard one, e.g., RISKMAN, CAFTA, or NUPRA. The primary document being reviewed is item 4, the PSABased TS Analysis or the PSA-Based TS submittal, but reviewers frequently obtain information from the other documents.

In addition, the plant's Technical Specifications and the Safety Analysis Reports, are expected to be used. Here, we briefly discuss the relationships among these documents.

\subsection{PSA, PSA-Review, and PSA Computer Code}

Generally, these three documents form the basis for PSA-based TS submittal. Usually, the general validity and accuracy of the PSA has been reviewed, and the responsibility of the reviewers of the PSA-based TS submittal involves reviewing the details of the PSA to understand how the TS parameters were modeled and the data were used in the analyses.

If the general validity and accuracy of the PSA has been reviewed, then it is expected that the comments will have been addressed and the document updated. It is most convenient for the reviewers to have the updated PSA, but if it is not available, then they need to make certain that all comments that affect the analyses of the changes in TS requirements are taken into consideration. Therefore, the reviewers may request information on how the comments were addressed in their TS analyses. The utility may respond with a list which includes each comment, an assessment of whether the requested change in the PSA affects the PSA-based TS analyses (a yes/no answer), and an explanation of how the comments were taken into consideration (for a "yes"), or alternatively, why the comment is not relevant to the submittal (for a "no").

The PSA computer code used in the submittal invariably is the same one used for the plant PSA. Typically, these codes (e.g., IRRAS, RISKMAN, CAFTA) are well known and have been used often. Reviewing the code is not the responsibility of the reviewers of the risk-based TS submittal. However, it may be desirable to run selective cases from the TS analyses to verify that the quantitative results follow the expected trend.

The reviewers are expected to use the same code and the same plant model as those used in the submittal to avoid differences in the results that could be attributable to differences in the computer codes or the plant model. Using the same version of the computer code is relatively easy; however, this may not always be so for the plant model because the utilities continually update the plant's PSA, and usually, keep only the updated version. At the time of the review, the updated version may differ if some time has elapsed since the analyses were completed. Then, it may be necessary to agree on a compatible version of the plant model with the utility, which can be used to cross-check some of the calculations in the submittal and those obtained from the current version of the plant 
model. This also is important because the reviewers may need to make additional calculations, or may ask the utility for additional evaluations that include quantitative analyses using the plant PSA model. Further, if there is an updated PSA model, the reviewers may need to verify that the TS analyses in the submittal are still applicable. In general, the updated model should be used to analyze TS changes.

\subsection{Review of the PSA for TS Applications}

A PSA is reviewed and accepted before it is used as a basis for TS change. NRC's review of PSA addresses its general validity and accuracy, but may not consider the adequacy of modeling of TS requirements, nor data relating to the plant's test and maintenance practices.

The review of the PSA-based TS submittal focuses on the TS contributors in the PSA; such contributors are those which define the risk contributions associated with the TS. For example, for evaluating an STI for a component, such TS contributions are defined by factors such as the component's unavailability, and the commoncause term relating to the component in the PSA. For the TS contributors, the PSA review needs to focus on four areas:

1. Whether the TS requirements being reviewed are included and adequately modeled in the PSA,

2. Whether all the risk contributions associated with the TSs being modified are quantified,

3. Whether the data used to quantify the TS risk contributions are valid, and

4. Whether the risk quantifications are correct, and include sensitivity and uncertainty studies.

Each of these areas is included in the next chapter where methodology of the review is discussed in detail. 


\section{METHODOLOGY OF THE REVIEW}

In this chapter, we summarize the methodology of the review of a PSA-based TS submittal, focussing on its technical aspects. We first identify the major areas that should be reviewed, and then briefly describe each of them, summarizing the issues for which the review will seek answers in the submittal.

The methodology presented here is based on research carried out in the United States and internationally. Specifically, the USNRC research projects on risk-based TS evaluations at Brookhaven National Laboratory, industry-sponsored researches on TS applications, and the work of the International Atomic Energy Agency (IAEA) on risk-based TS were considered in defining the methodology. ${ }^{1-7}$

\subsection{Issues Addressed in Review}

The basic objective of a review is to technically evaluate

a) the analyses supporting the requested changes, and the assumptions used,

b) the adequate treatment of issues arising from the requested changes,

c) the validity of the quantitative assessment, and

d) the framework used to develop the changes and the acceptability of the changes.

Specifically, the following items are focussed on:

- Reasons for requesting the modifications

- Calculation of applicable risk measures in quantifying the risk effects of TS modifications

- Adequacy of modelling the TS parameters in the risk model used to quantify the effects

- Data used to support the analysis

- Correctness of the quantifications performed

- Adequacy of the sensitivity and uncertainty analyses and their use to justify TS modifications

- Strategy used to define the requested TS change

- Presentation of results with sufficient details to allow their reconstruction.

\subsection{Reason for Requesting Modification}

The submittal should give the reasons for requesting the modification. When several requirements for change are included, then it may be necessary to give the reasons separately for each of them because there may be differences. From an analysis of the types of applications submitted, the reasons for requesting TS modifications may fall into one or more of the items presented below. Here, we discuss the reasons for requesting a TS modification, focussing primarily on the allowed outage time (AOT) and surveillance test interval (STI). 


\section{Improvement in Operational Safety}

The reason for TS modification may be to improve operational safety, that is, an improvement or reduction in the plant risk, or a reduction in occupational exposure of plant personnel in complying with the requirements. However, often the reason for the modification is to obtain operational flexibility, and it is argued that the changes will increase the allocation of plant personnel's time on safety-significant aspects, so improving operational safety.

\section{Consistency or Risk-Basis in Regulatory Requirements}

The changes requested in the requirements can be based on their risk implications. If the requirement has minimal implication on risk, then the changes may provide a needed flexibility. It must be assured that risk resulting from the change should remain acceptable. TS requirements can be changed to reflect improved design features in a plant that make a previous requirement unnecessarily stringent or ineffective. Risk-based analyses can justify the needed change and its risk implication.

\section{Demonstration of Need (burden considerations)}

The change may be needed to reduce the burden in complying with the requirements, based on the operating history of the plant, or industry in general. For example, in specific instances, the repair time needed may be longer than the allowed outage time (AOT) defined in the TS. The required surveillance may be ineffective in detecting certain failures of an equipment and need not be performed at the prescribed frequency.

The reasons for requesting changes can form an important input in the decision to seek the requested changes and define the evaluations necessary to justify the modifications.

\subsection{Applicable Risk Measures for AOT and STI Modification}

In a PSA-based analysis of TS changes, the risk impact is quantitatively evaluated using the plant-specific PSA. An important part of the review is directed at assessing whether the appropriate risk measures are calculated in the submittal. Applicable measures to be used for AOT and STI modifications are discussed in NRC publications. $^{1-3}$ The risk measures and analyses required to support these measures are described briefly, below.

\section{$\underline{\text { Level of Analysis }}$}

The impact of TS changes should be evaluated, where feasible, at least at the core-damage frequency (CDF) level of the plant, i.e., the measures discussed below are to be calculated in terms of core-damage frequency. In addition, an assessment is needed of whether the high consequence sequences are affected much more strongly than the low consequence sequences. A change in TS where CDF impact is negligible can be associated with large changes in the high consequence sequences, which may be unacceptable. For modifying TS on a containment system, a Level 2 PSA analysis is needed, i.e., an evaluation of the impact on release frequencies. This aspect is discussed in a little more detail in Section 5.2.1.

\section{AOT Risk Analysis}

For each of the requested AOT changes, the following risk measures need to be calculated to comprehensively describe risk impacts. Here, a list of the measures and a brief definition is given; a detailed description for these measures appears in Reference 1. 


\section{METHODOLOGY OF THE REVIEW}

a) Conditional risk during an AOT: the risk level (e.g., CDF), given that limiting condition for operation (LCO) was entered. This measure defines the conditional incremental CDF during the AOT.

b) Single-event AOT risk: the integrated risk (e.g., measured in terms of core-damage probability (CDP)) over an AOT period given that LCO was entered, i.e., the component or the train is unavailable. The increase in risk due to an AOT is measured when the increase in CDF (difference between the conditional $\mathrm{CDF}$ and the baseline $\mathrm{CDF}$ ) is used to estimate the CDP contribution. ${ }^{\dagger}$

c) Yearly AOT risk: the expected risk for the AOT duration due to LCO occurrences over one year. This measure takes into account the frequency of entry into $\mathrm{LCO}$, and is the product of this frequency and the single AOT risk.

d) Average yearly downtime risk: the expected risk over one year assuming the mean downtime for the duration in the LCO condition. Note, the single AOT risk and yearly AOT risk in b) and c) use the entire AOT, not the average downtime. This measure is taken into consideration when data analyses are provided to justify the mean downtime which is expected to be much less than the AOT. This mean downtime may not be impacted significantly by an extension of the AOT.

e) Risk level due to the preventive maintenance (PM) schedule: when AOTs are used for scheduled PM during power operation, then the risk impact of the PM schedule is to be calculated. For PM schedules, multiple components may be simultaneously unavailable, and accordingly, the CDFs associated with the PM are to be analyzed.

f) Increased risk due to simultaneous outages of components: if the changes in AOT could increase the possibility of simultaneous outages of multiple components, then this increased risk and how it is to be avoided during power operation should be analyzed and reviewed.

It is important to emphasize that both the single-event AOT and yearly AOT risk should be provided in evaluating AOT changes because the single-event AOT risk can be high and the yearly AOT risk still be low if the frequency of the AOT occurring is low. It should also be zoted that the single-event AOT risk contributions are probabilities and not frequencies, and their sizes must be assessed on a probability scale.

\section{STI Risk Analysis}

Surveillance tests are performed on safety-system components to detect failures that may have occurred during standby. In changing the surveillance test interval, the following measures should be evaluated (detailed discussions of the measures are given in Reference 1):

a) STI risk contribution or the test-limited risk for an STI: this measure defines the risk from failures that occur in an STI, or in between tests, and is detected by the test. It is calculated as the product of the reliability importance of the component and the average component unavailability due to failures occurring between tests.

†Core damage probability (CDP) contribution over a certain period is obtained by multiplying the conditional core damage frequency (CDF) during the period and the duration. Thus, the single-event AOT risk, which is a product of the increase in CDF and the AOT, is a probability. 
b) change in CDF due to changes in multiple STIs: this value can be calculated directly using the PSA where the unavailabilities of the respective component are changed, reflecting changes in the respective STIs.

c) impact of adverse effects of surveillance: when they are considered an important contributor, or an important reason for requesting the changes, then their contributions need to be quantified and assessed. Reference 1 discusses the particular calculations which need to be carried out.

\section{Total Risk Impact}

When multiple TS changes are requested, then the total collective risk impact from all the changes need to be reviewed. This includes:

a) the total impact of all the requested AOT changes,

b) the total impact of all the requested STI changes, and

c) the total impact of all the requested AOT and STI changes.

If multiple changes are made, the impact of each change is assessed individually, then as a check, the plant PSA is to be used to quantify the total impact.

\subsection{Modeling of TS Parameters}

In assessing a PSA-based analysis of TS changes, the primary question is the adequacy of specific aspects of the PSA model for the TS evaluation. Assuming that the plant PSA is adequate, the review of the TS submittal focusses on specific modeling items, namely whether the components whose TS are being analyzed for modification are explicitly modeled in the PSA. The model also should be able to treat alignments of components when testing and maintenances (scheduled and unscheduled) are carried out.

\section{Modeling of AOT Risk}

The following parameters that are important elements in determining the AOT risk contributions are addressed in the review:

a) the increased risk level (e.g., increased CDF level) when the component is down, and the assurance that the PSA is properly used in its calculation,

b) the distribution of maintenance downtimes used in the analysis, and their mean downtimes, and

c) the frequency for unscheduled (corrective) and scheduled (preventive) maintenances, particularly if their frequency is greater than once per year.

In items b) and c), it is particularly important that the basis for the extrapolated new mean downtimes and frequencies corresponding to the new proposed AOTs is reviewed.

\section{Modeling of STI Risk}

The following aspects important to modeling of STI risk need to be addressed in the review:

a) The basis for separating the demand versus standby time contribution to the component's unavailability: This corresponds to separating the component failure rate into a cyclic demand-related and time-related 


\section{METHODOLOGY OF THE REVIEW}

failure rate contribution. Only the time-related contribution is affected by the changes in the STI. The STI risk contribution can be underestimated if there is little basis for assuming a demand-related contribution.

b) Test-strategy considerations: If test strategies, e.g., sequential or staggered testing, are assumed, then how they are modeled is reviewed. Typically, PSAs do not assume any specific test strategies.

c) Assessment of common-cause failure contributions: When STIs are modified, then the common-cause contribution to failure for the affected components also is changed because the common-cause contribution is directly proportional to the STI. The review will address whether the modeling correctly evaluates such effects.

If the adverse effects of surveillance testing are quantified, then the modeling of such effects and how this contribution is used to assess STIs is evaluated (Refs. 1 and 7). Usually, many adverse effects of testing, namely, test-caused transients, and wear of equipment, are not separately modeled in a PSA, but are reflected in the initiating-event frequency and in the components' failure rates.

\subsection{Data Used in Support of Analysis}

For a quantitative analysis of the risk impact of TS changes, the data used have an important influence on the results obtained. Typically, data consist of: a) plant-specific data, b) generic data, and c) projected data for the proposed changes (due to lack of actual data). The objective of the review is to focus on consistent, adequate analyses, and the use of data in analyzing TS changes. The complete set of input data used in the PSA study is not necessarily the focus of the review; only relevant portions that influence the results of the TS analysis.

\section{$\underline{\text { Use of Plant-Specific Data }}$}

A request for plant-specific TS changes should use plant-specific data and not rely solely on generic data or data of similar plant designs. If plant-specific data are not used, then justification should be provided. If plantspecific data are insufficient and are used in combination with generic industry-wide data, then the review focusses on the way plant-specific data are treated. In general, there must be consistency. For example, when the increased risk for a TS change is assessed, plant-specific data should be used consistently in evaluating both the risk-impact of the existing TS requirement and that of the proposed changed requirement.

Specific data that are relevant for reviewing TS changes relating to AOTs and STIs are discussed below.

Repair/Maintenance Data: The repair/maintenance data for the components for which AOT changes are being requested are used to calculate the risk measures identified earlier:

a) Data on scheduled maintenances for scheduled maintenances performed during power operations: These data include the frequency and the expected duration of the maintenances which should include the waiting period for which the component is unavailable, along with the actual duration of maintenance. When plants use a "rolling maintenance" schedule, then data on simultaneous outages of multiple components, as planned in such a schedule, are relevant.

b) Unscheduled maintenance data: These include repair downtimes for unscheduled maintenances on the component. Again, the downtime should include the waiting period plus the repair time. The repairdowntime data can be described in terms of a distribution with a mean value and associated ranges. 
c) Reconfiguration data during maintenance: Reconfiguration of other components for maintenances may affect the risk-impact of a maintenance activity and should be presented, if credited in the analyses. These reconfigurations typically tend to decrease the risk-impact and can be neglected when conservative estimates are adequate.

Surveillance Test Data: The following surveillance test data are needed in analyzing STIs and are reviewed:

a) Detectability of the failure mode by the test: this includes an assessment of whether the failure mode contributing to the plant risk is detected by the surveillance test. An assessment of the component's failure data then may reveal the proportion of the failures detected by different activities. For example, plant walk-downs may detect $20 \%$ of the failures of a specific component despite the surveillance tests performed at a defined frequency. Typically, the failure modes modeled in the PSA are assumed to be detected by the surveillance test. However, if the submittal assumes that only a fraction of the failures are detected by the surveillance test, then this data should be carefully considered. The submittal may need to discuss the alternate activities that detect the failures in the context of the STI change, and their interface with the TS requirement.

b) Component failure rate: this rate typically is included in a PSA in determining a component's unavailability; it includes any separation by per demand (cycle) and time-related contributions, as discussed earlier.

c) Test-caused transient data: this includes errors caused during tests that result in plant transients. These data are needed to assess the adverse impact of testing, and can be used to justify increases in STIs. When such adverse effects are the reason for seeking STI changes, then these data should be presented.

Common-Cause Failures and Human Error Data: Common-cause failure and human error contributors in a PSA model can dominate the total CDF. Conservative estimates of these parameters can minimize and shadow the risk associated with TS changes whereas optimistic estimates can magnify the risk change (relative to the total CDF). The objective of the review is to make certain that realistic estimates for these parameters are used in the evaluation rather than unnecessarily conservative or optimistic estimates.

\subsection{Check on Quantification Performed}

One aspect of the review is to assure that the quantifications presented are correct. Usually, these quantifications are performed using a PSA computer code package. For example, the STP submittal, which is discussed in the example in Chapter 6, uses the RISKMAN computer code package developed by PLG, Inc., Newport Beach, California. Quantification is checked by repeating the calculations in the submittal. This is one of the most resource-consuming aspects of the review. However, all the calculations need not be repeated; selected ones can be re-quantified to assure that the results are correct. The number of re-quantifications will depend on the available resources. The selection can cover different types of TS changes (e.g., AOT change, STI change) and to include at least one of the changes showing negligible risk impact and another with large risk impact.

Such a review is not, however, a review of the computer code; for example, the RISKMAN computer code was not reviewed during the review of the STP TS submittal (discussed in Chapter 6). The quantification and methodology of the code is considered acceptable. If the code is to be checked, then an independent quantification needs to be carried out. The re-quantification process assures that, corresponding to the case analyzed, appropriate inputs and assumptions have been used. In essence, the objective of the review is to ascertain that the quantification process has: 


\section{METHODOLOGY OF THE REVIEW}

a)

no error of truncation: in quantifying the CDF, the accident sequence cut-sets are truncated at a certain value, e.g., $10^{-10}$, when quantifying the effect of TS changes. However, often, the affected contributors belong to cut-sets that may normally be truncated; this will be particularly true if low risk contributors are being used for proposed TS extensions. It is necessary that adequate precautions are taken to include such cut-sets because they are expected to influence the results.

b) appropriate calculation of conditional risk: the calculation of risk measures needed in an analysis of TS changes (AOTs and STIs) involve calculating conditional risk when a component or a train is unavailable (i.e., unavailability is equal to 1). Here, to obtain correct results, boolean reduction is necessary.

\subsection{Sensitivity and Uncertainty Analysis}

In a PSA-based analysis of TS changes, several assumptions and uncertainties affect the results. The quantification of the results discussed above usually are performed in terms of mean estimates of the PSA input data but providing point estimates of the CDF, and are considered adequate for TS risk analysis. However, these analyses should be supplemented by sensitivity and uncertainty analyses. In general, important assumptions are handled through sensitivity analysis supplemented by limited uncertainty analysis; this approach also limits the resources needed for these evaluations.

Sensitivity analyses are expected to address the following major issues or assumptions in the submittal that may affect the estimated core-damage frequency:

a) impact of variation in repair/maintenance policy due to AOT changes (e.g., scheduling a preventive maintenance of longer duration at power),

b) impact of variation in assumed mean downtimes or frequencies,

c) effect of separating the cyclic demand vs. standby time related contribution to the component's unavailability,

d) effect of simultaneous multiple component outages that may be likely due to changes in AOTs, and

e) impact of variation in common cause and human error contributions.

Uncertainty analyses can address the impact of uncertainties in the data in calculating the risk measures used. Their main function is to determine whether the TS changes will result in much larger uncertainty in the risk of the plant; for example, measured in terms of CDF. When multiple TS changes are requested, the impact of uncertainty in the new CDF incorporating all the requested changes is to be assessed.

\subsection{Strategy Used to Define the Requested TS Change}

The risk-based TS submittal will justify the requested TS change usually presenting various considerations in which a PSA-based evaluation is an important input. In reviewing the acceptability of the requested TS modification, the reviewer needs to consider the strategy used to arrive at the modified TS and the justifications. They must assure that the requested TS change is acceptable from engineering considerations, that PSA evaluations are appropriately used/blended with the engineering/regulatory considerations, and importantly, that the "defense in depth" concepts incorporated in the design of nuclear power plants are not violated. Consistent with previous NRC evaluation of TS modifications, the PSA evaluations should be judged considering: a) operating experience 
with the design, equipment, or specific plant, b) engineering/design analysis of plant configuration (including backup equipment), c) Standard Technical Specification (STS) requirement for a comparable plant design, and d) general conservatism in the evaluation.

\subsection{Presentation of Results}

Documentation of the detailed analysis supporting the TS changes is necessary. The information analyzed should be succinctly presented in the utility submittal, not only for the reviewers to understand the analysis performed and the assumptions made, but also for future reference in regulatory decisions both by the plant staff and the USNRC. The documentation should cover all the aspects discussed below:

a) reasons for the request,

b) identification and discussion of the issues supporting the requested changes,

c) models and data used for quantitative analyses,

d) assumptions in the analysis,

e) presentation of quantitative results with relevant intermediate results,

f) sensitivity/uncertainty analyses,

g) strategy used to define the requested TS change, and

h) presentation of any alternatives studied.

In addition, a summary should be given of the requested changes, reasons for them, impact of the changes on plant risk, any changes in plant procedures or activities, and the safety and operational benefits to be gained from the changes. 


\section{REVIEW STEPS}

In this chapter, we define the steps for reviewing a PSA-based TS submittal.These steps are defined based on the experience gained in our review of the South Texas Project TS submittal (discussed in Chapter 6), and on other research carried out on PSA-based TS analyses. The broad steps defined here provide significant flexibility for reviewing the detailed analyses that may vary from one submittal to another.

\subsection{Steps in the Review Process}

The review of a PSA-based TS submittal preferably should be conducted in six major steps. Breaking up the review in this way allows: a) an early decision on a submittal substantially deficient in quality, b) a structured interface between the reviewers and the utility who prepared the submittal for obtaining additional information, and c) preparation of interim findings. Above all, it will assure effective use of resources and timely completion of the review.

Some of the steps can or should be initiated in parallel to save time. However, as structured, Steps 1 and 2 must be completed first.

The following are the broad steps of the review:

1. Identify the type and reasonableness of the requested TS change

2. Make a Qualitative Review of Submittal and Requested TS Changes

3. Make a Provision for Independent Quantitative Assessment

4. Make a Detailed Review of the Analyses Supporting Requested Changes

4.1 Analyses of Issues Addressed

4.2 Quantitative Assessments

4.3 Categorization of the requested changes

5. Undertake Quantitative Analyses Supporting the Review's Conclusions

6. Give Technical Conclusions on the requested changes

\subsection{Review Steps and Findings}

\section{Step 1. Type and Reasonableness of the Requested TS Change}

This first step is a broad overview of the submittal to identify the type of TS change being requested and the reasonableness of the request. This step requires review of selected portions of the submittal to extract the relevant information. The items to addressed are presented in check-list 1 in the next Chapter (Table 5.1). Essentially, the reviewers need to judge if the requested changes make engineering sense, and if the assessed risk impact will be acceptable to allow the change in TS.

If the submittal is rejected, then a clear justification of the reasons should be prepared. This justification can be based on the argument that engineering evaluation does not support the change (explaining the engineering evaluations performed) and/or the assessed risk impact of the change requested by the utility is unacceptable. 
At the conclusion of this step, the findings should include the following:

1. The reasonableness of the requested TS changes, i.e., the requested changes can be accepted if the analyses presented are valid and sufficient,

2. Justification if the submittal is to be rejected; an explanation of why the requested change is considered unreasonable and why of the analyses were not reviewed.

\section{Step 2. Qualitative Review of Submittal and Requested TS Changes}

This step is a qualitative review of the submittal to assess its adequacy, and any need for additional information to conduct the detailed review and to reach technical conclusions. No quantitative reassessment of the PSA-based results is necessary; however, the reviewers should assess if there is adequate information (as defined in Table 5.2, Check-list 2) to carry them out later. In short, a quick overview of the entire submittal is recommended, accepting the quantitative results being presented to make early judgments. Any missing information needed for this step can be resolved with the utility.

At the conclusion of this step, the findings should include the following points:

1. Judgment on the adequacy of the submittal, i.e., the submittal contains the necessary results and provides sufficient details for the review. The items defined in the check-list (Table 5.2) are covered in this review finding.

2. Identification of any additional information needed by the review team in the form of a list of questions; this list may include any omissions in the submittal, as evident from checking against the items in Table 5.2 (and considering the additional items in Table 5.3).

\section{Step 3. Make a Provision for Independent Quantitative Assessment}

A review of the submittal involves a quantitative assessment of the risk impact of the changes. As discussed in the methodology (Chapter 3), this includes selective quantitative reassessment of the results in the submittal and any additional calculations made by the reviewers. The review team should develop the capability for independent quantitative assessment. This step should assure that a comparable, acceptable PSA model, and computer code is available to carry out the evaluations.

Typically, the activities involve obtaining the PSA model and the computer code, assuring that it covers the review comments on the PSA, performing and comparing the base-case PSA results and a few PSA-based calculations needed for TS analyses, and gaining confidence that independent evaluations can be undertaken. This step includes resolving any discrepancies in the calculated results between the review team and the utility.

The findings for this step can be summarized as follows:

1. The PSA computer code, plant model, and database needed for the review are available for quantitative analyses.

2. If there are acceptable differences between the results in the submittal and those obtained by the review team, then justification for the differences and the way they will be handled in the review should be defined. 


\section{REVIEW STEPS}

3. If the differences are not resolvable, this should be documented and the review terminated, requesting further analyses by the utility.

\section{Step 4. Detailed Review of the Analyses Supporting the Requested TS Changes}

This step involves detailed review of the submittal. Here, analyses of the issues identified in the methodology of the review are conducted, which include selected re-quantification of the risk measures calculated by the utility. This step carries out the bulk of the review and provides much of the basis for the technical conclusions. This step can be started in parallel with Step 3.

The following are the specific activities in this step:

1. Analyses of the TS issues addressed in the submittal and those applicable for the proposed changes,

2. Quantitative assessment of the results presented, and

3. Categorization of the requested TS changes in terms of their risk impacts.

The items 1 and 2 above are discussed in depth in Chapter 3, and the check-list of items in Chapter 5 should assure that the review is complete. The proposed TS changes should be categorized into groups, based on their risk impacts; examples are given in Chapter 6. These groupings may define a) those TS changes with negligible risk impacts, b) those changes with minor risk impacts where there are alternate means of controlling the risk increase, and c) those changes where risk impacts are judged substantial.

The review findings of this step can be summarized as follows:

1. Categorization of the requested TS changes, based on their risk impacts;

2. Identification of any requested TS change that may be rejected because the analyses of relevant issues are inadequate, and/or the change involves larger risk impact than that calculated, and

3. Identification of additional calculations that the review team must make.

\section{Step 5. Quantitative Analyses in Support of the Review's Conclusions}

The review team may undertake certain quantitative analyses to support their conclusions:

a. Assessment of the total risk impact of a smaller subset of the requested changes. The reviewers may judge that some of the requested changes are not acceptable and may want to be assured that total risk impact of the changes being accepted is small, as intended, by excluding some of the requested changes.

b. Assessment of an additional requirement in approving the requested change; in some cases, the requested change may be approved with additional requirements, e.g., staggered testing, cross-train check before scheduled maintenance, or tightening another TS requirement. In those cases, quantitative analyses may be needed to justify the technical conclusions of the review team.

c. Additional sensitivity analyses; the review team may perform additional sensitivity analyses to gain confidence that the results presented are not sensitive to modeling and data assumptions. These types of sensitivity analyses are defined in Chapter 3. 
The review findings of this step can be summarized as follows:

1. The results of the additional analyses performed by the reviewers and their implications for the conclusions,

2. Identification and documentation of any additional requirements applicable to the requested changes, and

3. Any safety lessons learned from the independent analyses undertaken in reviewing the submittal.

\section{Step 6. Technical Conclusion on the Requested Changes}

In this final step, the information analyzed earlier should be considered together to arrive at the technical conclusions, including the quantitative and the qualitative justifications. The technical conclusions and the reasons for them should be succinctly summarized, presenting each of the requested changes, the technical conclusions on their acceptability, and any additional requirement that may be desirable. A table similar to Table 6.6, presented in Chapter 6, can be used to summarize these conclusions.

The review findings of this step are:

1. List of the requested changes, technical conclusions on the changes, and any suggested additional TS requirement, and

2. Summary discussion on the technical conclusions. 


\section{CHECK-LIST OF ITEMS FOR REVIEWING PSA-BASED TS SUBMITTAL}

In this chapter we define a check-list of items for reviewers of PSA-based TS submittals. The submittal may be a substantial document providing many PSA-based results and addressing the issues defined in Chapter 3. Also, as discussed in Chapter 2, other documents (the plant's PSA, the Review of the PSA, and the PSA Computer Code) comprise part of the submittal and are used during the review. Thus, a check-list of items would be convenient for the reviewers to assure that the relevant issues have been addressed and reviewed appropriately.

A review of a PSA-based TS submittal may involve several individuals from USNRC and from outside contractors with expertise in this type of analysis. Typically, when the changes requested involve many TS requirements and/or substantial analyses are submitted to support these changes, individuals outside the USNRC may be involved in the technical review. In such a situation, the NRC staff first evaluates whether the submittal is adequate for a detailed review. At this time, an initial qualitative review of the submittal is needed to determine whether sufficient analyses have been provided, or the submittal may be returned to the utility to request the missing elements or to obtain justifications why these aspects do not need to be addressed in these TS changes. A similar qualitative review also is needed for the people who will be conducting the detailed review to first familiarize them with the submittal and to identify additional information to be requested from the utility.

\subsection{Check-List of Items for Review}

We present three check-lists, each of which is connected with specific activity and relates to a specific review step discussed in the previous chapter. The checklists are used to determine if the next phase of the review should be started; they allow for an early termination of a review, if warranted.

Check-list 1 (Table 5.1) evaluates the type of the requested TS change, and its reasonableness.

Check-list 2 (Table 5.2) can be used for a qualitative review of the submittal, to evaluate the adequacy of the analyses performed and the information provided.

Check-list 3 (Table 5.3) addresses the specific issues that should be considered during the detailed review of the submittal.

The first checklist identifies the type of the submittal and the justification presented. Any unreasonable request can be identified, and an approach to reviewing a reasonable request can be defined. The second check-list accommodates an approach whereby a detailed quantitative review is preceded by a qualitative one which evaluates the adequacy of the analyses performed and information provided in the submittal. When all relevant information are found to be available so that a detailed review can proceed, then the use of the third check-list assures that relevant issues applicable to the analysis in the submittal are addressed.

The following sections briefly describe the three check-lists.

\subsection{Check-List 1: Type and Justification of the Requested TS Changes}

Check-list 1 (Table 5.1) supports a broad overview of the submittal to make an early determination about the reasonableness of the requested TS changes. This check-list corresponds to Review Step 1 presented in the previous chapter. It covers four areas, identifying the types of the requested changes, using the PSA-based method to analyses the TS changes, applying engineering considerations in accepting the changes, and assessing the riskbased justifications for the changes. 
Table 5.1 List of Items to Determine the Type and Reasonableness of the Requested TS Changes

\section{A. Type of TS Modification Requested}

The type of TS modification requested can include:

1. Changes of AOTs

2. Changes of STIs

3. Changes of both AOT and STI for the same safety system trains

4. Changes in test strategy requirements

\section{B. Use of PSA}

Questions to be answered in determining the way the PSA is used include:

1. Was the PSA used to analyze the impact of TS changes?

2. Was the PSA reviewed by the NRC Staff before its use for TS application?

3. Are the PSA model and the software used for the analyses available to the reviewers?

C. Acceptability from Engineering Considerations

Engineering issues to be discussed in justifying the changes include:

1. Engineering considerations that support the requested changes,

2. Existing regulatory requirements are not contradicted by the requested changes.

\section{Risk-Based Justification for the Change}

The type of risk argument used to justify the requested changes can include:

1. Net reduction in risk,

2. No net increase in risk,

3. Minimal increase in the risk measure (e.g., CDF),

4. Sizable increase in risk, but reduction in operation-related burden.

Additional risk-related arguments can include:

1. Operational Flexibility,

2. Optimizing resources,

3. More thorough reporting.

The justification of the type of changes requested help reviewers to focus on the corresponding items in the check-lists presented later, and the issues to be addressed in the review. The items in the check-list on using PSA address the review of the PSA and the availability of the PSA models and the software. As discussed earlier, the general validity and accuracy of a PSA should be reviewed before using it for a TS application. These issues must be resolved before starting a review of the TS submittal. 


\section{CHECK-LIST OF ITEMS}

The requested TS changes must be acceptable from engineering considerations. As discussed earlier, a TS change is finalized based on inputs from various considerations where PSA-based analysis is an important input and justification. If these issues cannot be resolved satisfactorily, then TS changes will not be acceptable, and further review may not be necessary. The risk-based justifications for the requested TS changes also address their reasonableness. Review can proceed if these justifications are acceptable. If the change implies a sizable increase in risk, unacceptable to NRC, then the review can be completed explaining this reason for rejecting the requested TS changes.

\subsection{Check-List 2: Qualitative Review of Risk-Based TS (AOT/STI) Submittal}

Check-list 2 (Table 5.2) provides a list of items that should be used to conduct a qualitative review of a risk-based TS submittal requesting modification to AOT and STI requirements. This check-list corresponds to Review Step 2, discussed in the previous chapter.

This check-list discusses the type of risk to be evaluated, the PSA modeling necessary for evaluating AOTs and STIs, the risk contributions for the proposed changes, the use of data in the analyses, and sensitivity and uncertainty analyses supporting the quantitative analysis presented in a submittal.

\section{The Level of the PSA Which can be Used for AOT and STI Evaluations}

The level of the PSA refers to the type of risk which is evaluated by the PSA. A Level 1 PSA evaluates the core-damage frequency. A Level 2 PSA also evaluates the frequency of radioactive releases from the containment for different release categories. A Level 3 PSA goes further and also evaluates the health risks to the public in terms of the frequencies of early and latent fatalities. A Level 1 or Level 2 PSA generally is sufficient for risk-based AOT/STI evaluations, since assuring that they have acceptable contributions to the core-damage frequency or release frequencies will ensure their having acceptable contributions to health risks.

A Level 1 PSA is adequate for AOT/STI evaluations if the associated component or components which are being evaluated are in systems whose function is to prevent core damage and if their failure does not adversely affect the amount of radioactivity which can be released. These accident prevention systems generally include the emergency power systems, reactor shutdown systems, and emergency coolant systems with their associated support systems.

A Level 2 PSA evaluation is desired if the failure of the component or components associated with the AOTs or STIs can potentially significantly increase the radioactivity releases due to a postulated accident. These components generally involve components in systems whose function is to mitigate consequences from an accident. Containment systems and spray. systems, along with their support systems, are prime examples of these systems.

If a component can be involved in both preventative and mitigative functions, then the impact of modifying the AOT or STI on both the CDF and releases needs to be evaluated. Evaluating the impacts on the frequency of release categories will not necessarily involve a complete Level 2 PSA if screening-type arguments can show that the proposed modifications have no adverse impacts on the releases. 
Table 5.2 Check-List for Review of a Risk-Based TS (AOT/STI) Submittal

\section{A. Type of Risk Evaluated}

\section{Level of PSA Used}

Level 2 PSA (releases and frequencies)

Level 1 PSA (CDF)

Function/System unavailability

\section{Analysis Using Different Levels of PSA}

If Level 2 is not used, are the consequences considered for components in the containment or mitigative systems?

If function/system unavailabilities only are evaluated, are the interfaces with other systems considered?

\section{B. Aspects of Modeling Used}

\section{Details of PSA Modeling}

Is the modeling clear and consistent?

Is the modeling done to the level of a train or component level?

If the AOT/STI components are in support systems, are all the support interfaces modeled?

If train level or modular level only is used, are the system interfaces and common-cause failures addressed?

- $\quad$ sequence level calculations based on the train's contributions

- $\quad$ treatment of train-level CCFs

\section{Results on the Risk Impacts of Individual AOTs}

\section{Yearly AOT Risk Impact from Each AOT}

Are the absolute and relative contributions provided?

Are the absolute and relative change for the proposed AOT modification given? 
CHECK-LIST OF ITEMS

Table 5.2 Check-List for Review of a Risk-Based TS (AOT/STI) Submittal (Cont'd.)

\section{Single-Event AOT Risk from Each AOT}

Are absolute and relative contribution provided?

Are absolute and relative change for the proposed AOT modification given?

Are dominant contributors to each AOT risk impact discussed?

D. Results on the Risk Impacts of Individual STIs

\section{Risk Impact from Each Proposed STI}

Are absolute and relative contribution to risk using the STI risk measures provided?

Are absolute and relative change in risk due to the proposed changes given?

Are dominant contributors to each STI risk impact discussed?

E. Results on the Risk Impacts of the Total Set of AOTs/STIs

Total Risk Impact of the Set of Proposed AOTs/STIs

Are absolute and relative contributions using the risk measures presented?

Are absolute and relative changes in risk due to the proposed changes given?

Total Risk Impact of the Set of Proposed STIs

Are absolute and relative contributions using the STI risk measures provided?

Are absolute and relative change in risk due to the proposed changes given?

\section{Total Risk Impact of the Set of Proposed AOTs}

Are absolute and relative contribution using the AOT risk measures provided?

Are absolute and relative change in risk due to the proposed changes given?

Is risk impact from multiple downed components presented? 
Table 5.2 Check-List for Review of a Risk-Based TS (AOT/STI) Submittal (Cont'd.)

\section{F. Data Used for the Evaluations}

Data and Justifications Provided for AOT Evaluations

Is downtime length for each AOT given?

Is downtime frequency for each AOT given?

Is basis for extrapolation of the length of downtime presented?

Is basis for any reductions in the frequency of downtime presented?

Data and Justifications Provided for STI Evaluations

Is the failure rate for each STI component given?

Is the basis for per-demand contribution to the failure rate given?

\section{G. Uncertainty and Sensitivity Evaluations}

Uncertainty and Sensitivity Evaluations for AOTs

Are general sizes of uncertainties described?

Are sensitivities due to human errors considered?

Are sensitivities due to common-cause failures considered?

Are sensitivities due to using total AOT evaluated?

Uncertainty and Sensitivity Evaluations for STIs

Are general sizes of uncertainties described?

Are sensitivities due to human errors considered?

Are sensitivities due to common-cause failures considered?

Are sensitivities due to separating the component failures into time-related (per-hour failure rate) vs. demand-related (per-demand contribution) failures evaluated? 


\section{CHECK-LIST OF ITEMS}

The Detail of PSA Modeling Necessary for AOT and STI Evaluations

To properly evaluate the risk contribution of AOTs/STIs, the PSA needs to be modeled in sufficient detail. The following sections describe the level of detail needed in a PSA model to adequately evaluate the associated risk contributions.

\section{The Detail Necessary for AOT Evaluations}

For AOT evaluations, it is sufficient if the PSA is modeled to the basic component level for the components whose AOTs are being evaluated. Also, the functional interfaces of the AOT components with all other components should be modeled explicitly; this is particularly important for the components of support system which can interface with multiple components and systems. The standard event-tree models and fault-tree models used in a PSA contain this detail of modeling when support-system interfaces are modeled explicitly. Truncation of the minimal cutsets can underestimate AOT risk contributions. Hence, the set of minimal cutsets used must be checked to assure that they contain the downed component.

For a particular AOT component, the other components which are reconfigured when the component is down also should be identified unless justification is given that, by not considering the reconfigurations, the evaluated risk impacts from the AOT will be higher than if such reconfigurations were considered.

When an AOT is entered due to equipment failure, the conditional core damage frequency during the outage of that equipment will be sensitive to common cause failures that could impact similar equipment or redundant trains. The reviewer must be satisfied that the common cause failure parameters are appropriately modified to reflect this interaction in calculating the conditional core damage frequency. The common-cause failure contribution is evaluated in the quantifications; however, the PSA modeling should identify the other components in redundant trains which can be involved in the common cause failures. Component-level fault-tree models generally do this, provided that the components are not truncated out to simplify the models.

Even when a PRA is modeled to only the train or super component level it may still be adequate for AOT evaluations, provided it can address the issues that are significant to the submission. To demonstrate this, it must be shown that the risk impact from the train or module being down is equal to, or larger than, the impact from the component being down. This is applicable to a train containing the component, or module of components in series (an "OR" gate). Also, it must be shown that all the component's functional interfaces are properly included by modeling only to a train or module level. For AOT components in a support system, this demonstration can be difficult. Furthermore, the effects of reconfigurations of other components, if these are carried out, must be shown to be properly handled or bounded by the train or module modeling. Also, components and trains must be properly linked, i.e., properly combined, to obtain the sequence-level contributions. Finally, common-cause failure contributions at the component level must be properly or conservatively handled by the defined trains or modules. Since these justifications can be difficult, it generally is more direct to model to the component level.

\section{The Detail Necessary for STI Evaluations}

The detail necessary for STI evaluations is similar to that for AOT evaluations. Component-level modeling in the PSA is sufficient to properly include the STI contributions. The functional interfaces of the STI components with other components should be explicitly modeled in the PSA. Since other components generally are not reconfigured when given components are tested, this issue generally is not important for STI modeling. Like AOT contributions, STI contributions can be sensitive to common-cause failure contributions, and the PSA model should be sufficiently detailed to identify the other components in the redundant trains which can be involved in the common-cause failures. 
To properly use train-level modeling for STI evaluations, the component's failure-rate contribution to the total train failure rate value used must be identified. As for the AOT evaluations, it must be shown that the risk increases from component failures are properly evaluated with the train models, and that functional interfaces as well as common-cause failures are incorporated properly. Again, because of the difficulties which can be encountered in preparing these justifications, it is generally better to model at the component level for STI evaluations.

\section{Results of the Risk Impact of AOTs/STIs}

Items C,D, and E in Table 5.2 address the results of evaluating the risk impact for the AOT and STI changes which should be presented in the submitted. These items (Section 3.3) cover the results to be presented for individual evaluations, and for the total set of AOTs and STIs. Here, we explain the items in the check-list.

\section{AOT Risk Contributions: Absolute and Relative Contribution, Dominant Contributors}

For AOT evaluations, the results to be presented consist of single-event and the yearly AOT risk contributions for each proposed AOT. The absolute value of these contributions is calculated using the proposed AOT. Its relative value is calculated using the relative value of the contribution from the baseline risk level (e.g., the baseline CDF). Changes in the contribution using the increase in the AOT from the present value represent the risk change due to the proposed changes. Both the absolute value and the relative value calculated using the baseline risk-level should be given.

The contributors to the results are the basic factors causing the results to have their values; these are the reasons for the results. Of particular importance are the reasons for low AOT risk contributions or for high AOT risk contributions. These reasons, or contributors to the results, generally involve other key components or basic events in the same minimal cutset as the AOT. For example, an AOT risk contribution may be small because of the small unavailability of the other components in the minimal cutset. Conversely, the AOT risk contribution may be large because of a high probability of human error in the same minimal cutset as the AOT. The contributors, or reasons for the results, also can involve assumptions of a small AOT duration or a small frequency of occurrence of the AOT. The dominant reasons for to each AOT risk contribution can be identified in a simple table with accompanying short descriptions.

\section{STI Risk Contributors: Absolute and Relative Contribution, Dominant Contributors}

For STI evaluations, different STI risk contributions should be presented. When only the risk from occurrences of failures between tests, i.e., the test-limited risk is relevant, then this contribution should be presented. When the adverse effects of testing are evaluated, then the relevant test-caused risk should be given (Ref 1 discusses these STI risk contributions). Similar to the AOT contributions, the absolute and relative contributions and absolute and relative change due to the proposed changes should be given.

The contributors to the STI results which explain the reasons and causes for the results should be described. The contributors involve high or low unavailabilities of other key components which cause the STI contributions to be high or low. They also involve assumptions of a low or a high failure rate for the component. A simple table can be prepared, identifying these dominant contributors and reasons.

\section{Risk Impact of the Total Set of AOTs/STIs}

When both AOTs and STIs are proposed to be modified, then the total risk contribution for the set of modified AOTs and STIs should be presented. Since only the yearly AOT risk contributions are additive, the yearly 


\section{CHECK-LIST OF ITEMS}

AOT risk contribution for several AOTs is meaningful. Single-event AOT contributions to risk are not added since they do not accumulate. Each single-event AOT contribution is a conditional risk contribution, when the component is down for a given AOT. The total STI risk contribution from a set of STI modifications is not necessarily the sum of the individual STI risk contributions, and has to be evaluated separately.

When the AOT is to be used to take multiple components down for preventive maintenance, then the risk impact of such maintenance schedules also should be described (Ref. 1).

\section{Data Used for the Evaluations}

The data used in quantifying the AOT risk contributions consists of:

The length of downtime,

The frequency of downtime,

The common-cause failure probabilities.

The downtime length is the assumed time for which the component is down for the AOT. If the total AOT is not used for the downtime, then justification for its length should be given, including the bases used for extrapolating from available data and bases for the distribution of downtime used.

The downtime frequency is the frequency at which the AOT is expected to occur. The frequency includes not only downtimes due to failures but also those due to corrective or preventative maintenances. The basis for the downtime frequency and associated uncertainties should be identified.

Common-cause failure probabilities involving the components whose AOT is being modified should be given separately. The parameters of the common-cause failure model used also should be included. A simple table with these data values is recommended.

The data used in quantifying the STI risk consist of :

The test interval,

The component's failure rate,

The common-cause failure probabilities.

The test interval is what is being proposed for the component. The component's failure rate is based on generic data and/or plant-specific data. The bases for the failure rate value used and associated uncertainties should be given. If the failure rate is divided into a per-demand and a per-hour contribution, then the basis for the former must be documented thoroughly. This is important, as the assumption of any nonzero per demand contribution decreases the STI risk contribution which is due only to the per-hour failure rate contribution."

"The contribution of the per-demand failure rate represents failures caused by testing while that of the per-hour failure rate represents failures occurring between tests. 
Common-cause failure probabilities involving the components whose STI is being modified should be provided separately and should include the parameters of the common-cause failure model used. A simple table with these values is recommended.

\section{Uncertainty and Sensitivity Evaluations}

The use of uncertainty and sensitivity evaluations in risk-based TS evaluations is discussed in Section 3.7, and a check-list of relevant issues is provided in Item $G$ of Table 5.2. Specific guidance on this aspect was not developed as part of this study.

\subsection{Check-list 3: Detaited Review of Risk-Based TS Submittal}

Check-list 3 (Table 5.3) lists the items relevant to detailed review of a risk-based submittal of AOT and STI changes; it corresponds to Review Step 4 in the previous chapter.

This check-list contains additional items that are not covered in the previous two. It is to be used in the detailed review of the quantitative results calculated using the PSA model and the data for TS analyses. Thus, this check-list addresses PSA modeling of TS parameters, PSA-based quantification, use of plant-specific data, and two special areas; the use of AOT to conduct PM, and the adverse effects of surveillance testing. These items are not described separately here as they can require long discussions. A person involved in a detailed review is expected to be familiar with the items presented here, and also can refer to NUREG/CR-6141, Handbook of Methods for Risk-Based Analyses of Technical Specification (Ref.1). This check-list is expected to remind the reviewer of the important issues to be addressed, and is not meant as a step-by-step analysis of a submittal. 
Table 5.3 Check-List for Use During the Detailed Review

A. PSA Modeling of TS Parameters

1. Are the components/systems for which TS changes are being considered explicitly modeled?

2. Is the basis for the distribution of repair time for the proposed AOT provided?

3. Is the maintenance frequency affected by the AOT change? Is the estimation of maintenance frequency given?

4. Is the component's unavailability due to random failures modeled in terms of its failure rate and the test interval?

5. Is the component's unavailability separated into the demand vs. standby failure contribution? Is the basis for this separation given and is this data clear?

6. Is any specific test strategy for the redundant trains modeled in the PSA? If so, is this explained adequately?

7. Is any adverse effect of testing quantified? Are the parameters and data used in modeling such effects presented?

B. PSA Quantification Consideration for TS Risk Analyses

1. If truncated cutsets are used to quantify the impact of TS changes, then were precautions taken to include the cutsets containing the TS item?

2. Are the truncation levels for quantification discussed?

3. Are the components and trains appropriately linked to obtain sequence contributions?

4. In calculating the conditional CDF when a component is failed or taken down:

a) Is the appropriate boolean reduction process used?

b) If any reconfiguration of components are used, are they defined?

c) Are the common-cause failure terms appropriately modified to calculate the conditional CDF?

C. Use of Plant-Specific Data

1. Are plant-specific data used consistently?

- When the increased impact (e.g., increase in CDF) of a TS change is assessed, are plant-specific data consistently used in both cases?

When plant-specific data are available, are their uses consistent in different cases? 
Table 5.3 Check-List for Use During the Detailed Review (Cont'd.)

2. Repair/maintenance data

- Are the following items included in repair/maintenance data for the components affected by the requested change provided?

a) frequency and downtime of scheduled maintenance,

b) frequency and downtime of unscheduled maintenance,

c) reconfiguration of other components credited in the analysis,

d) outages of multiple components during scheduled maintenance.

3. Surveillance test data

- Are surveillance test data impacting the analyses summarized in the submittal? This data should include:

a) detection of the failure mode by the test assumed in the analysis; separation of demand and standby failure contributions,

b) test interval and the standby failure rate in the PSA-model,

c) any data on adverse effects of testing used in the analysis,

d) common-cause failure parameters used in the analysis.

D. For Use of AOT to Conduct PM

If AOT is used to conduct PM, are following PM risk contributions presented?

1. Risk impact of a fixed routine PM schedule

2. Contribution to the average plant CDF

3. CDF peaks due to simultaneous outages of multiple components taken out-of-service for PM

\section{E. Surveillance Test Interval Analyses Incorporating Adverse Effects of Testing}

If adverse effect of testing is used to justify increasing an STI, then the analyses should include:

1. qualitative analyses of the adverse effects when the risk increase for the change is small,

2. quantitative analyses when the risk effect is not small.

For each of the following adverse effects, the analyses should consider

a) test-caused transients: plant-specific data and analyses of transients caused by the test and why reduction in such transients is unlikely,

b) test-caused degradation: justification of the degradation caused by the test,

c) restoration error following a test: analyses showing why restoration errors cannot be reduced. 


\section{EXAMPLE OF A REVIEW OF A PSA-BASED TS SUBMITTAL}

In this chapter, we give an example of a review of a PSA-Based TS submittal to demonstrate the review process discussed earlier in this report. We use the Houston Lighting and Power's (HL\&P) submittal to modify the Technical Specifications (TS) at the South Texas Project (STP) Electric Generating Station Plants, hereafter called the STP submittal. The STP submittal contained the type of TS changes discussed in this report, and was reviewed by the NRC relatively recently. There are other examples of reviews of PSA-based submittal; and also, TS requirements for advanced nuclear power plants that are being reviewed using PSA-based methods. ${ }^{10}$

The methodology of the review, and the review steps presented in the earlier chapters, were used in the review of the STP submittals and refined from the experience gained. The check-lists of items (Chapter 5) were defined using the experience of the review of STP submittal.

Here, we present an overview of the STP submittal, and the findings in each review step. We concentrate on the technical conclusions of the requested changes, based on the detailed assessment of the STP submittal.

By STP submittal, we mean the original submittal (Ref. 11) and responses to requests for additional information (Ref. 12, 13, and 15).

\subsection{STP PSA-Based TS Submittal, STP PSA, and Review of STP PSA.}

Houston Lighting \& Power (HL\&P) submitted an amendment to modify the Technical Specifications (TS) of the South Texas Project (STP) Electric Generating Station plants on February 1, 1990. This amendment proposed changes to 22 Technical Specification items and was based on probabilistic safety assessment (PSA) analysis of the impact of changes on plant risk.

The risk-based analysis of STP Technical Specification modifications was carried out using the STP probabilistic safety assessment (PSA) completed in May 1989, and reviewed by Sandia National Laboratories for the NRC. ${ }^{16,17,18}$ The STP PSA employed the RISKMAN Computer Code package developed by PLG, Inc.. ${ }^{19}$ The review of the STP PSA by Sandia did not involve any quantitative evaluation using this code. After completing the STP PSA, STP staff then used it to develop a submittal for Individual Plant Examination (IPE) of the plant. The risk model supporting the IPE differs from the original PSA model. The core-damage frequency estimated in the IPE submittal is about a factor of 4 lower than the estimate in the May 1989 analysis. Similarly, the impact of TS changes evaluated using the STP IPE model differs, and was reassessed by STP in August 1993. This analysis, based on the STP IPE model, was used to evaluate the impact of the proposed TS changes, and was used in reviewing the requested modifications.

After starting the review of the STP submittal, BNL maintained a technical contact with STP staff to obtain necessary information for reviewing the TS analyses. The review was started with the original submittal, which was supplemented by STP staff with additional evaluations using the IPE model while it was in progress. STP also provided an earlier version of the IPE (RISKMAN) model which was used for quantitative analyses of TS changes; later, they provided an upgraded version of this model. The first-phase review findings, requesting additional evaluations to support the proposed TS changes, were summarized in question form and sent to STP ${ }^{14}$. STP's revised submittal which was issued in response, and which included reassessments, was reviewed. The revised version also was supplemented with additional information during the final review process. This additional information related to the questions raised about the original submittal. This information also was considered in the review. 


\subsection{Proposed TS Changes for STP Stations}

The STP consists of two units (STP 1\&2), Westinghouse-designed pressurized water reactors (PWRs). Unit 1 and 2 have been operating commercially, since August 1988 and June 1989 respectively. In general, the plants have three electrically independent and physically separate safety trains. As stated in the STP submittal, the current TSs are generally based on the Standard Westinghouse Technical Specifications which were developed for Westinghouse two-train designs. The proposed changes primarily consist of extending allowed outage times (AOTs) and Surveillance Test Intervals (STIs) to take credit for the added safety resulting from the three-train design.

Of the 22 proposed changes contained in the original submittal, six were withdrawn by STP. Table 6.1 lists the remaining 16 TS changes, reviewed here, and summarizes the specifics of the proposed individual changes.

Of the 16 proposed TS changes, quantitative evaluations are performed by STP in support of 11 of them using the PSA model of the plant. STP gave qualitative explanations for the remaining 5 to support their proposed extensions.

Two types of TS change are requested by STP:

a) extending the allowed outage time (AOT) for a single train failure (e.g., from a current limit of 3 days to 10 days),

b) extending the surveillance test intervals (STI) (e.g., from 31 days (monthly) to 92 days (quarterly)).

The TS changes are either one of the two types ( 8 only AOT changes, 4 only STI changes) or both (4). Of the 11 changes for which PSA quantitative evaluations are presented, 5 relate to AOT changes only, 2 relate to STI changes only, and the remaining 4 involve both changes.

\subsection{Scope of the Review}

The scope of the review was to technically evaluate the STP submittal requesting modification of the TS requirements. This technical evaluation was to include an independent quantitative reassessment, as necessary, of the impact of the proposed TS changes on the plant's risk, using the plant's PSA. Because the PSA used the RISKMAN Computer Code package, the review also was carried out with the same code so that the quantitative results could be compared. The review of the original submittal, completed in May 1993, included a requantification of selected aspects. Additionally, the core-damage frequency impact of the technical review conclusions was quantitatively assessed using the STP PSA model and the RISKMAN computer code.

The review submittal focussed on the TS changes for which quantitative assessments were presented, i.e., the 11 TS changes indicated above. The remaining 5 TS changes, with qualitative analyses, were not reviewed. The Level 1 internal event PSA was used for reviewing the technical analyses in the submittal. For 2 of the changes involving containment systems, the Level 2 internal event PSA was used.

The review did not comprehensively examine the basic STP PSA (STP PSA of May 1989, STP IPE, August 1992) nor the RISKMAN Computer Code package. (The STP PSA of May 1989 was reviewed by Sandia National Laboratories). The review team accepted the PSA made available to them by STP. Selected aspects of the PSA involving modeling of TS parameters that directly affect the TS analyses were found to be adequate. 
Table 6.1 Proposed Modifications to the South Texas Project Technical Specifications

\begin{tabular}{|c|c|c|c|c|}
\hline \multirow[t]{2}{*}{ System } & \multicolumn{3}{|c|}{ Proposed Modifications } & \multirow{2}{*}{$\begin{array}{l}\text { Type of Analysis } \\
\text { Done by STP }\end{array}$} \\
\hline & AOT (Days) & & I (Days) & \\
\hline Chemical and Volume Control (i.e., Charging Pumps) & $3->10$ & & $\mathrm{~N} / \mathrm{C}^{*}$ & System, Core Damage \\
\hline Reactor Protection & $\mathrm{N} / \mathrm{C}$ & 62 & $\rightarrow>92$ & System, Core Damage \\
\hline Engineered Safeguard Features Actuation & $\mathrm{N} / \mathrm{C}$ & 62 & $->92$ & System, Core Damage \\
\hline Pressurizer Safety Valves & $15 \mathrm{~min}->1 \mathrm{hr}$ & & $\mathrm{N} / \mathrm{C}$ & Qualitative \\
\hline Accumulators & $1 \mathrm{hr} \rightarrow 12 \mathrm{hrs}$ & & $\mathrm{N} / \mathrm{C}$ & System \\
\hline Emergency Core Cooling & $3 \rightarrow 10$ & & $\mathrm{~N} / \mathrm{C}$ & System, Core Damage \\
\hline Residual Heat Removal & $3->10$ & 92 & $->184$ & System, Core Damage \\
\hline Containment Ventilation & $\mathrm{N} / \mathrm{C}$ & 31 & $->92$ & Qualitative \\
\hline Containment Spray & $3->10$ & 92 & $->184$ & $\begin{array}{l}\text { System, Core Damage, } \\
\text { Release Frequency }\end{array}$ \\
\hline Reactor Containment Fan Coolers & $3->10$ & 31 & $-->92$ & $\begin{array}{l}\text { System, Core Damage, } \\
\text { Release Frequency }\end{array}$ \\
\hline Containment Isolation & $4 \mathrm{hrs} \rightarrow 24 \mathrm{hrs}$ & & $\mathrm{N} / \mathrm{C}$ & Qualitative \\
\hline Steam Generator Safety Relief Valves & $4 \mathrm{hrs} \rightarrow 24 \mathrm{hrs}$ & & $\mathrm{N} / \mathrm{C}$ & Qualitative \\
\hline Component Cooling water & $3 \rightarrow>10$ & & $\mathrm{~N} / \mathrm{C}$ & System, Core Damage \\
\hline Control Room HVAC & $\begin{array}{c}7 \mathrm{~d}(1 \mathrm{t}), 24 \mathrm{hr}(2 \mathrm{t})--> \\
10 \mathrm{~d}(1 \mathrm{t}), 72 \mathrm{hr}(2 \mathrm{t})^{* *}\end{array}$ & 31 & $->92$ & System, Core Damage \\
\hline Electrical Auxiliary Building HVAC & $\mathrm{N} / \mathrm{C}$ & $12 \mathrm{hrs}$ & $->24 \mathrm{hrs}$ & Qualitative \\
\hline Essential Chilled Water & $3->10$ & & $\mathrm{~N} / \mathrm{C}$ & System, Core Damage \\
\hline
\end{tabular}

$\begin{array}{ll}\text { Notes: } & \text { N/C means No Change Requested } \\ & (1 \mathrm{t})=\text { First Inoperable Train } \\ & (2 \mathrm{t})=\text { Second Train of Three }\end{array}$ 
The STP submittal proposes to change the TS requirement of both units. In the STP analyses presented, these two units are not treated separately. No interdependencies or cross-connections were identified in the STP evaluation that would cause the units to be separately analyzed; hence, they were not separately treated in the review.

\subsection{Overview of the Review Steps and the Findings}

In this section, we summarize the review of the STP submittal corresponding to the review steps discussed in Chapter 4, which included limited, selective quantitative reassessments. We also discuss the assumptions used in the review.

1. The primary reason for the STP submittal requesting changes to a number of AOT and STI requirements was that the Westinghouse (W) Standard Technical Specifications (STSs) do not give adequate credit for the three, separate safety-train design of STP plant because the STSs were developed for two-train safety systems. The STP submittal analyzed extended TS requirements which will confer adequate operational flexibility for a three-train design, demonstrating that the proposed TS extensions cause negligible increases in risk, i.e., negligible increases in CDF, and negligible large, early-release frequencies for TS changes involving containment systems. In principle, the requested TS changes made engineering sense, i.e., from engineering considerations, it was acceptable that AOT and STI requirements for a three-train redundancy should be more flexible than a corresponding two-train design (Review Step 1).

2. A qualitative review of the STP submittal (Review Step 2) identified the additional information needed by the reviewer (Refs. 8, 12). To save time, while undertaking this second step of the review, the third step also was in progress, establishing a capability for independent quantitative assessment (Review Step 3).

This request for additional information by the review team involved additional evaluations by the utility and details of the new evaluations. The review of the STP submittal resumed when response to this request was received ${ }^{11}$, which was supplemented with additional analyses later ${ }^{13}$.

3. During the later phases of the review, the quantitative analyses presented in the submittal were considered valid and correct. As mentioned briefly in Section 6.3, during the first phase of the review, which resulted in the request for additional evaluations, selected re-quantification was undertaken. In all cases, the same numerical results were reproduced.

4. During the detailed review of the analyses (Review Step 4) supporting requested changes, each of the requested changes was reviewed individually first, and then an assessment was made, based on the combined overall impact. The intent was to focus on the risk impacts of the individual changes, and then evaluate the overall risk impact, noting the importances of individual contributions.

5. As discussed later in this chapter, the TS changes were categorized into those having negligible impact on plant risk, and those whose impacts are not necessarily negligible. Following this, some additional aspects were judged qualitatively. For example, the total impact of the group of the TS changes whose individual impact on the average CDF is negligible, also is assessed to be negligible.

6. Because of constraints in time and resources, no additional quantitative sensibility analyses evaluating effects of modeling and data assumptions were made (maximum values were assessed using the results presented by the submittal). The conclusions of the technical reviewers on additional TS requirements (e.g., cross-train check, staggered testing) were based on qualitative judgments and the available 


\section{EXAMPLE OF A REVIEW}

quantitative analyses (Review Step 5). However, a quantitative evaluation was performed to assess the total impact of the conclusions of the technical review.

7. In arriving at the final technical conclusions (Review Step 6), the results of the quantitative and qualitative aspects both were considered. Reviewers, including the NRC staff, met to discuss the review's findings and the available options to assure that relevant technical aspects were addressed adequately.

\subsection{Review of STP Methodology for Proposed TS Modifications}

In this section, we briefly summarize the methodology used in the STP submittal to quantitatively assess the risk impact of the requested TS changes. We focus on using the risk measures in modeling the TS parameters and on the sensitivity and uncertainty evaluations of the submittal. The STP submittal included the original submittal (Ref. 11) and responses to requests for additional information (Refs. 12, 13, and 15). As evident from the discussion, some issues were satisfactorily addressed in response to these comments.

\subsubsection{Assessment of the STP Methodology Used to Calculate the AOT Risk Contributions}

The STP submittal used a valid, general methodology to calculate the risk contributions which are associated with the proposed AOTs. This general methodology is described in NUREG/CR-6141 (Ref. 1), NUREG/CR-5200 (Ref. 2), and NUREG/CR-5425 (Ref. 3).

The STP PSA model explicitly included the components whose AOT was being evaluated, and the associated parameters (frequency of unscheduled and scheduled maintenance, distribution of mean downtimes) which were used to quantify the risk effects of the requested changes.

The STP submittal (Ref. 11) primarily calculated and justified changes to AOTs based on the average CDF contribution for them. In this calculation, the submittal focussed on the downtimes due to unscheduled maintenances. However, STP calculated the single-event AOT risk and gave a detailed analysis of the impact of the maintenance schedules used during power operation for preventive maintenance.

The STP submittal provided an evaluation using the system's unavailability and the core-damage frequency (CDF) of the plant for each changes requested. Also it gave the total impact of the changes, considering different release groups (See Table 6.2). For the containment systems, the impact on large, early-release frequency was supplied in response to the request for additional information.

The STP submittal calculated the point estimates to evaluate the CDF contributions of AOT changes, and provided an uncertainty analysis for all the requested changes. This calculation was the mean estimate for the CDF contributions, and the associated uncertainty range, which was similar to that estimated in the PSA.

The STP submittal assumed a mean downtime for the proposed AOT, i.e., on the average 1/6 of the proposed AOT would be used in any downtime. This assumption was based on extrapolations from generic downtime data for smaller AOTs, i.e., three-day AOTs, as opposed to 10-day ones which generally were requested. Since there were no hard data to obtain the mean downtime for the proposed AOT, we estimate the maximum contributions which represent the maximum risk allowed by the AOT when the total AOT is used for repair or maintenance. These maximum values were used to categorize the risk impacts from the proposed AOTs (See Section 6.7). 


\subsubsection{Assessment of the STP Methodology Used to Calculate STI Risk Contributions}

The STP submittal used a valid, general methodology to calculate the risk contributions from the proposed extended STIs. The component failure rates were treated as being totally standby time-related (on a per-hour basis) which maximizes their risk contributions. Lacking data to separate the demand-failure contribution and standby time-related contribution, this treatment of component failure rate is appropriate. The general STI methodology which covers these considerations is summarized in NUREG/CR-6141 (Ref. 1), and discussed in NUREG/CR-5200 (Ref. 2), and NUREG/CR-5775 (Ref. 7).

The STP model explicitly included the components for which a change in STI was being evaluated and appropriately accounted for the common-cause failure contribution when an STI was being changed. The STP submittal did not request, nor provide an analysis of the effect of a different test-strategy. When the SIT is being changed to six months, as in the submittal, evaluation of a staggered test-strategy and its benefits would have been useful.

The STP submittal did not evaluate the uncertainties associated with each of the STI risk contributions, but carried an uncertainty analysis considering all the requested changes; the impact on the uncertainty range for the CDF was small.

\subsection{General Observations Regarding STP Submittal Impacting Review of the Requested TS Changes}

In this section, we present some general observations relating to the CDF impacts presented in the STP submittal. Many of these observations involve considerations of the risk level in the plant, and the effect of plant practices.

Baseline Core Damage Frequency (CDF) Level of the Plant

The baseline CDF for the STP plant used for the analysis is $4.4 \times 10^{-5}$ (point estimate) with a range factor (e.g., ratio of $95 \%$ and $50 \%$ estimates of CDF) of around 2.5 . This estimate is referred to as the STP PSA/IPE estimate. The mean CDF for the STP plant is not exceedingly low, but lies in the middle of the range of CDFs for wider ranges of plants and analyses, as was evident from other IPE submittals. In other words, the three-train design of the STP plant did not result in a particularly low CDF compared to two-train designs.

\section{Reduction in the STP CDF Estimate}

The executive summary of the STP submittal gives a table showing the history of the calculated CDF:

\begin{tabular}{|c|c|c|}
\hline STP PSA (1989) & STP PSA/IPE (1992) & Current Evaluation $(1993)^{13}$ \\
\hline $1.7 \mathrm{E}-04 \mathrm{yr}^{-1}$ & $4.4 \mathrm{E}-05 \mathrm{yr}^{-1}$ & $3.6 \mathrm{E}-5 \mathrm{yr}^{-1}$ \\
\hline
\end{tabular}

It is important to note that none of these decreases was due to the proposed TS changes, but, as discussed in different parts of the submittal, was due to a combination of reasons. The decrease in Level 2 PSA/IPE estimate from the Level 1 PSA estimate primarily results from: (1) improving the RISKMAN computer code, (2) removing conservatism in the PSA model, and (3) using limited plant-specific data. 


\section{EXAMPLE OF A REVIEW}

The decrease in Current Evaluation (1993) from the PSA/IPE estimate is due to changes in planned maintenance practices at the plant, reflects a change to semiannual maintenance as opposed to quarterly maintenance for emergency diesel-generators, auxiliary feedwater and essential chilled water systems. This decrease in maintenance and the corresponding decrease in maintenance unavailability is the primary reason for the decrease in CDF from the 1992 PSA/IPE assessment; it is not related to the TS change. As analyzed in the STP submittal, the TS changes requested increase in the average CDF by approximately $6 \%$ (at least $10 \%$ when the impact on initiating events is included) when only a mean repair time is assumed, i.e., on the average, only 1/6 of the proposed new AOTs are used. When the entire AOT is used, the increases in the CDF can be significantly higher (Section 6.5).

\section{Impact of the "Rolling Maintenance" at the Plant}

As stated in the STP submittal, the allowed outage time (AOT) in the STP TS is used to plan maintenance during power operation using a rolling maintenance schedule. A "12-week rolling maintenance schedule" is used at the STP plant. In each of these 12 weeks, all planned, and to the extent possible, corrective maintenances are scheduled, together with any required surveillance testing according to a predetermined schedule. In such a schedule, a defined set of equipment (i.e., safety trains) is taken out-of-service, each week, and the schedule repeated every 12 weeks. The rolling maintenance has dual effects: (1) improving the reliability of the equipment, which decreases the average plant CDF in the long run, and (2) increasing the downtime associated with maintenance, which increases the plant CDF. Typically, in PSA models, a conservative approach is taken, i.e., only the second effect is included. As analyzed in the submittal, the planned maintenance increases the CDF by about $47 \%$, where the mean duration of the maintenance downtime is used. If the increased AOTs are used to perform longer maintenances, then the increase in CDF will be higher than the value determined in the STP submittal. However, as stated there, the total maintenance downtime due to planned maintenance per system train per year is expected to remain the same (or even be reduced) when AOTs are increased because the increase in the duration for a maintenance also will involve less frequent maintenance.

\section{Surveillance Testing and Preventive Maintenance}

As stated in the STP submittal, the surveillance testing at the STP plant "is accomplished at the conclusion of the planned maintenance period to prove the equipment operable." The coordination of the surveillance testing and preventive maintenance is desirable to reduce the equipment's downtime. However, when surveillance testing intervals are increased to a value equal to, or larger than, the planned maintenance interval, and if such testing are performed at the end the planned maintenance, then one aspect of surveillance testing may be lost, i.e., to detect any failure during the standby period. In other words, planned maintenance may correct many failures but the component's reliability, measured from the results of surveillance testing, may be unrealistically high for actual demands on the component. Thus, surveillance testing will continue to verify periodically the operability of the equipment, but the meaning of the surveillance data for monitoring reliability is less clear.

\section{Assessment of the Impact of Changing Surveillance Test Intervals}

The impact of changes in the surveillance test intervals (STIs) is incorporated in the component unavailability model used in the PSA, where an increase in STI increases the component's unavailability and consequently, the CDF.

However, the component failure rate $(\lambda)$ used in the component unavailability model can be a function of the STI and a significant increase in STI may increase the $\lambda$ because surveillance testing, like preventive maintenance, has beneficial influence on a component's reliability. In a surveillance test, the component's operability is enhanced whereby its piece-parts are lubricated, accumulated dirt is cleaned up, which otherwise could 
contribute to an increased likelihood of failure. In PSA analyses, changes in $\lambda$ are not modeled, since it is considered that STIs are not being changed beyond the point where they may affect $\lambda$. Although the relation between $\lambda$ and STI for different components is unknown, caution should be taken when significant changes are proposed for STIs, based on risk analyses showing negligible increases where $\lambda$ is assumed to remain constant for larger extrapolations. It can be useful to monitor the performance of these components, for example, by establishing a reliability monitoring program, to assure that there are no deleterious effects from extending the STI.

\section{Total Impact of the Requested TS Changes}

Table 6.2 summarizes the total risk impact of the proposed AOT and STI changes. As shown, the expected risk increases are not significant, but are not necessarily negligible. The maximum increases which occur if the total AOT is used are appreciable.

The STP analysis calculated the system contributions to the CDF for the proposed changes to STIs and AOTs. This allowed the increases in CDF to be evaluated by system which, in turn, identified the subset of systemproposed changes which resulted in negligible CDF increase and those which did not. The same system breakdown can be used to analyze the increases in the release frequencies using the Level 2 PSA analyses.

As calculated in the STP submittal (Table 6.2), the expected increase in large, early-release frequency (LERF) is 35\% from the proposed TS changes (item I in the table). There was no breakdown of this contribution due to each of the proposed changes. However, it was noted that this increase is due almost entirely to the AOT and STI changes in the control room's HVAC system.

Table 6.2 Summary of the Risk Increases Due to the Proposed AOT and STI Increases ${ }^{+}$

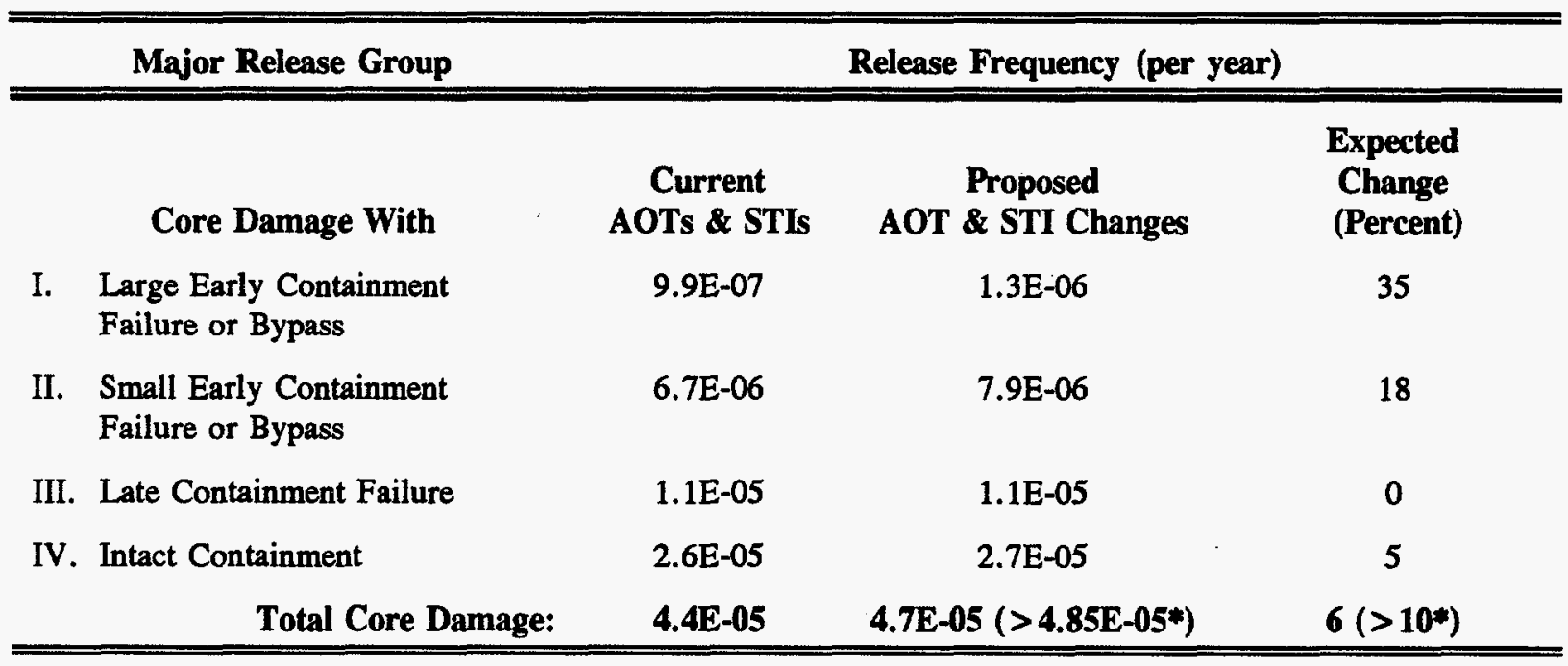

+ Reproduced from Table 3.1.6 of Reference 13

* Value including the impact of changes in Essential Chilled Water System on the initiating-event frequency (see Table 3.1.1, page 3.1.6, Note (3) of Reference 13). 
As presented, the average CDF is increased by $6 \%$ (10\% when the impact of changes to initiating-event frequency is included). ${ }^{\dagger}$ Since the entire AOT may be used, although infrequently, the impact of individual TSs using the entire AOT also should be included in assessing the risk impacts.

\section{Limited Plant-Specific Experience Data}

The risk-based analysis of TS changes in the STP submittal includes limited data from plant-specific experience. For example, the durations of corrective maintenance used are from generic industry databases (except for one case) and do not necessarily reflect STP plant experience. The primary reason for this is that the plants have been in operation only for about five years. However, the submittal used plant-specific information to analyze the planned maintenance presumably because more data were available here.

\subsection{Analysis of Requested Technical Specification Changes}

In this section, we evaluate the risk-based analyses in the STP submittal. Here, we summarize the relevant considerations in analyzing the requested changes and their categorization, based on their risk impacts. Evaluations of the requested TS changes also are discussed.

\subsubsection{Categorization of Proposed Changes in STP Submittal Based on the Impact on Average Plant CDF}

The STP submittal takes the position that the calculated risk impacts from all the proposed TS extensions are negligible. However, from the review of the sizes of the risk impacts, the proposed TS extensions in the STP submittal can be more accurately grouped into three categories:

1. Proposed TS extensions which result in basically zero or near zero CDF increases (Table 6.3).

2. Proposed TS extensions which result in CDF increases which are not necessarily negligible (Table 6.4).

3. Proposed TS extensions involving containment systems where the impact on release frequencies need to be assessed (PSA Level 2 Analyses) (Table 6.5).

The categorizations of the specific proposed TS extensions are shown in the following three tables. Category 1 proposed TS extensions basically only affect the CDF, and cause zero to near zero CDF increases for the expected increase in CDF and the maximum CDF (Table 6.3). The increase in expected CDF corresponds to STP's assumption that only $1 / 6$ of the extended AOT will be used, on average. The maximum increase in CDF corresponds to the case where the total extended AOT is used because of the longer repairs required. When the AOT risk contribution is a dominant contributor to CDF, then the increase in CDF is directly proportional to the assumed fraction of the AOT used. The CDF increases for the HVAC, at the bottom of the Category 1 table, are $3 \%$ (maximum increase may be as large as $18 \%$ ) and their negligibility is borderline. One reason for including Control room HVAC system in Category 1 is that the conditional CDF for a failure in the system is a factor of 1.6 larger than the baseline CDF. Category 2 TS items increase conditional CDF by more than a factor 2. Category 2 proposed TS extensions produce increases in expected CDF and maximum CDF which are not necessarily

$\lceil$ Based on our assessments, the impact of TS changes on the initiating event (IE) frequency should be included in the CDF impact, and should not be treated separately. The STP analysis did not evaluate the CDF impact considering all the proposed changes in which the impact on IE frequency for changes in Essential Chilled Water System is included. The review analysis did not precisely quantify this contribution, but only placed a lower bound on the value, as indicated in Table 6.2. 
negligible, especially for the latter (Table 6.4). Since there are no direct data supporting the assumption of $1 / 6$ of the AOT being used, the maximum AOT risks need to be considered to bound the maximum increase in risk. The maximum AOT risks also account for uncertainties in the PSA calculations. Category 3 proposed TS extensions were evaluated additionally for their impact on large, early-release frequency contributions using PSA Level 2 analyses (Table 6.5).

Table 6.3 Category 1 Proposed TS Extensions Which Result in Zero to Near Zero CDF Increases

\begin{tabular}{|c|c|c|c|}
\hline System & $\begin{array}{l}\text { Proposed } \\
\text { TS Change }\end{array}$ & $\begin{array}{l}\text { Expected } \\
\text { CDF Change } \\
\text { (Percent) }\end{array}$ & $\begin{array}{c}\text { Maximum CDF } \\
\text { Change } \\
\text { (Percent) }\end{array}$ \\
\hline $\begin{array}{l}\text { Chemical and Volume Control System } \\
\text { (CVCS) }\end{array}$ & $\begin{array}{c}\text { AOT } \\
3 \rightarrow 10 \text { Days }\end{array}$ & $\sim 0.0^{*}$ & $\sim 0.0 * *$ \\
\hline Accumulators (ACC) & $\underset{1 \mathrm{hr} \rightarrow 12 \mathrm{hr}}{\text { AOT }}$ & $\sim 0.0 *$ & $\sim 0.0^{*}$ \\
\hline $\begin{array}{l}\text { Engineered Safety Feature Actuation } \\
\text { System (ESFAS) }\end{array}$ & $\underset{\substack{\text { STI } \\
2 \mathrm{mo} \rightarrow 3 \mathrm{mo}}}{ }$ & 0.1 & 0.1 \\
\hline Residual Heat Removal (RHR) & $\begin{array}{c}\text { AOT } \\
3 \rightarrow 10 \text { Days } \\
\text { STI } \\
3 \mathrm{mo} \rightarrow 6 \mathrm{mo}\end{array}$ & 0.1 & 0.6 \\
\hline Reactor Protection (RPS) & $\underset{2 \mathrm{mo} \rightarrow 3 \mathrm{mo}}{\mathrm{STI}}$ & 0.6 & 0.6 \\
\hline Component Cooling Water (CCW) & $\begin{aligned} & \text { AOT } \\
& 3 \rightarrow 10 \text { Days }\end{aligned}$ & $-* * *$ & - \\
\hline $\begin{array}{l}\text { Control Room Heating, Ventilation, and } \\
\text { Air Conditioning (HVAC) }\end{array}$ & $\begin{array}{c}\text { STI } \\
1 \mathrm{mo} \rightarrow 3 \text { mo } \\
\text { AOT } \\
7 \rightarrow 10 \text { Days } \\
(1 \text { st Train) } \\
24 \rightarrow 72 \mathrm{hrs} \\
\text { (2nd Train) }\end{array}$ & 3 & $<18$ \\
\hline
\end{tabular}

* Based on calculated negligible increases in the system's unavailability.

** Negative because of changes in PSA modeling, and not due to the AOT change.

*** Expected CDF change presented in the STP Submittal includes interaction not applicable to the STP plant (verbal communication with STP). The single AOT risk is negligible, based on the conditional CDF calculation for this LCO provided by STP. 
Table 6.4 Category 2 Proposed TS Extensions Resulting in CDF Increases not Necessarily Negligible

\begin{tabular}{cccc}
\hline \multicolumn{1}{c}{ System } & $\begin{array}{c}\text { Proposed } \\
\text { TS Change }\end{array}$ & $\begin{array}{c}\text { Expected } \\
\text { CDF Change (\%) }\end{array}$ & $\begin{array}{c}\text { Maximum } \\
\text { CDF Change (\%) }\end{array}$ \\
\hline \hline Emergency Core Cooling (ECC) & $\begin{array}{c}\text { AOT } \\
3 \rightarrow 10 \text { Days } \\
\text { AOT } \\
\text { Essential Chilled Water (ECW) }\end{array}$ & 3.3 & 20 \\
\hline \hline
\end{tabular}

$\dagger$ Including the impact on IE frequency, in Table 3.1.1 of the submittal. ${ }^{13}$

Table 6.5 Category 3 Proposed TS Extensions Involving Containment Systems

\begin{tabular}{lcccc}
\hline \hline \multicolumn{1}{c}{ System } & $\begin{array}{c}\text { Proposed } \\
\text { TS Change }\end{array}$ & $\begin{array}{c}\text { Expected } \\
\text { CDF Change } \\
(\%)\end{array}$ & $\begin{array}{c}\text { Maximum } \\
\text { CDF Change } \\
(\%)\end{array}$ & $\begin{array}{c}\text { Contribution to Large, } \\
\text { Early, Release Frequency } \\
\text { (LERF) Change* }\end{array}$ \\
\hline \hline $\begin{array}{l}\text { Containment Spray } \\
\text { (CS) }\end{array}$ & $\begin{array}{c}\text { AOT } \\
3 \rightarrow \text { 10 Days } \\
\text { STI }\end{array}$ & 0.0 & 0.0 & 0.0 \\
$\begin{array}{l}3 \text { mo } \rightarrow 6 \text { mo } \\
\text { AOT } \\
\text { Reactor Contain- } \\
\text { (RCFC) }\end{array}$ & $\begin{array}{c}\text { AOn Cooler } \\
\text { 10. Days } \\
\text { STI } \\
\text { ST } \rightarrow 3 \text { mo }\end{array}$ & 0.0 & 0.0 & 0.3 \\
CS and RCFC & & & 0.3 \\
\hline \hline
\end{tabular}

* Accounts for approximately 80 percent of the total LERF.

\subsubsection{Analysis of TS Changes with Negligible CDF Impacts}

The following aspects of requested TS changes with negligible CDF impacts were additionally assessed to determine their impacts further. These assessments were bounding ones, based on the quantitative assessments presented in the submittal.

Conditional risk due to use of AOT: The increase in conditional risk (increase in conditional core damage frequency multiplied by the requested AOT) for each of the TS changes was found to be small. The conditional CDF calculated for each of the LCO for which TS changes were being requested was less than a factor of 2 .

Impact on individual initiating event category: The impact on CDF due to each of the individual initiating-event categories (e.g., loss of coolant accident (LOCA), Station Blackout) is not expected to be significantly altered by this subset of TS changes. The STP submittal gave the impact of all the 11 requested TS changes on each of the 
major initiating-event categories, which was reviewed. A similar analysis for this subset of TS changes is expected to show that there is no significant alteration of the relative contribution of the categories.

Simultaneous outages of multiple components: With the increase in AOTs, there is an increasing likelihood of multiple components being simultaneously out-of-service for maintenance. The planned maintenance performed in a rolling maintenance schedule results in a different combination of equipment being taken out-of-service every seven days. With a 10-day AOT, for instance, there would have to be a control in place disallowing the start of planned maintenance the following week, if any unanticipated problem arises during the first week resulting in maintenance beyond seven days. To eliminate this possibility, AOTs of seven days can be an appropriate alternative, which still provides a significant portion of the requested extensions.

Total operating risk impact of this subset of TS changes: The total impact of this subset of TS changes was not evaluated separately, but from the evaluations given, this impact also is expected to be negligible.

Risk of shutting down the plant: The risk of shutting down the plant with the proposed changes to TS was not evaluated. This aspect does not need to be addressed in most cases where the risk of shutting down is much smaller than that for continuing operation. However, for residual heat removal (RHR) systems, the change in test interval from 3 to 6 months can adversely affect the risk of shutting down. (It is noted that in the STP plant, the importance of RHR systems is less than in other plants.) In addition, as discussed earlier, this large test interval can change the component's failure rate, and the overall unavailability of the train can be large.

Test Strategy Considerations: The STP submittal does not discuss the test strategy (e.g., sequential, staggered) for the proposed STI changes. Staggered testing reduces the risk impact compared to sequential testing, and the increase in risk due to increases in STIs can be compensated for by using a staggered test strategy ${ }^{21}$. One important reason for this risk benefit is that common-cause failure of multiple trains will be detected earlier. In a staggered test strategy, for a $n$-train system with a test interval $T$, each train is tested at $T / n$ time-units apart; for example, in a 3-train system with a STI of 6 months, at least one train is tested every 2 months. Since the effect of a large test interval (e.g., 6 months for RHR System) on the component's failure rate and common cause failure is not known, staggered testing is considered applicable for these types of changes to STIs. Staggered testing is expected to detect failures in this system earlier if this large STI has any adverse effects.

Impact of Changes on Large, Early Release Frequency (LERF) Contribution: The STP submittal had a single evaluation of the impact to major release groups combining the effects of all the AOT and STI changes requested. The LERF increases by 35 percent due to the requested changes, with the total LERF absolute contribution being 1.3E-06. The evaluation showed that the increase in the LERF contribution is almost entirely due to changes in the AOT and STI control room HVAC. Because of this large relative impact on LERF, there is questionable basis for the proposed AOT extension for the first train failure in control room HVAC.

In summary, the requested AOT and STI changes for the seven TS items discussed above were assessed to have negligible risk impacts, with the following restrictions:

- AOT of 7 days should be used instead of 10 days to minimize simultaneous outages, and

- Staggered testing should be required when changing the STI to 6 months for the RHR system to minimize the risk impacts of the extension.

The changes to this category of TS items, as identified in Table 6.3, consequently are assessed to involve negligible risk impact, and, in addition, are expected to provide the operational flexibility where resources can be spent on risk-significant problems. 


\subsubsection{Analysis of TS Changes with Non-Negligible Impact on Average Plant CDF}

Two of the requested TS changes, (Table 6.4), are considered to have non-negligible impact on plant risk. In both cases, the requested TS change involves increasing the AOT from 3 to 10 days. Based on the quantitative assessment in the submittal, the impact of changing these AOTs can have the following implications:

- As stated in Chapter 3, in defining AOT, not only should the average impact on plant CDF be evaluated, but also the risk contribution for a given LCO. The conditional CDF when the component is down for an AOT is approximately increased by a factor of 2 to 3; if the entire AOT is used, the core-damage probability (CDP) contribution will range from $2 \times 10^{-6}$ to $4 \times 10^{-6}$, i.e., approximately a 5 to $10 \%$ of the base CDP contribution for the year. It is acknowledged that every time the LCO is entered, the entire AOT is not expected to be used; nevertheless, this measure is important because the entire AOT may be used and such contributions may be incurred.

- The impact discussed above is due to unplanned maintenances. In addition, the planned maintenances for these systems contribute additional risk. As discussed in the STP submittal, the 12-week maintenance cycle can increase the baseline CDF by $47 \%$ a good portion of which is contributed by the maintenance of these specific systems. The proposed extended AOTs for these systems will not necessarily be restricted to unplanned maintenances, and if these extended AOTs are used to increase the duration of planned maintenances without decreasing their frequency, then a non-negligible additional increase in risk will be incurred. The STP plan for rolling maintenance does not call for increased duration for planned maintenance if an increase in AOT is approved. Nevertheless, there is a substantial effect on CDF from planned maintenance of these systems.

- Based on the information in the STP submittal, these specific systems are taken out-of-service frequently; on the average, one train of each of the system is maintained once every month in a 12-week maintenance cycle. A 24-week maintenance cycle will imply maintenance of one train of the Essential Chilled Water System once every 2 months. Thus, the maintenance downtime contribution for these systems is already significant.

- There is no strong evidence in the submittal to justify the increase in the AOT, despite the non-negligible risk impact of these requirements.

The alternatives considered by the reviewers in evaluating changes to the requirements for these two systems are as follows:

- Require a cross-train check of one of the redundant trains to assure its availability before the AOT is used to perform an unplanned maintenance, i.e., repair a failure; this will reduce the impact of the downtime.

- Allow a longer AOT only for unplanned (or unscheduled) maintenances; i.e., a different TS requirement for planned and unplanned maintenances.

- Justify that adequate repair cannot be completed within the current AOT, and that the risk of shutting down the plant is equal to, or larger than, that of continued operation.

In summary, the review concluded:

a) the requested change in the AOT for the Essential Chilled Water (ECW) System involves a non-negligible increase in risk and the alternatives considered are not analyzed sufficiently to justify the proposed change nor an alternate one. 
b) The AOT for the Emergency Core Cooling System (ECCS) can be extended to 7 days with minimal risk impact if a cross-train check of a redundant train is instituted before an unplanned maintenance, i.e., to repair a failure.

\subsubsection{Analyses of TS Changes Involving Containment Systems}

The TS changes involving containment systems minimally impact the large, early-release frequency (LERF) of the plant (Table 6.5). The reason for this small impact on LERF is attributed to the specific design features of the STP containment. The containment building is a post-tensioned concrete cylinder, with a steel liner and a domed top. The internal diameter is 150 feet, the walls are 3 to 4 feet thick, and the steel liner is $3 / 8$ of an inch thick. During the review, no PSA Level 2 evaluation was performed. The review did not find any significant issues in STP analysis showing minimal impact on LERF (Table 6.5). follows:

Using reasonings similar to those discussed for other TS items, the assessments for these TS items are as

- Negligible risk impacts will result if the AOT for the Containment Spray (CS) System is extended from 3 to 7 days. If staggered testing is performed, then the STI can be extended to 6 months with minimal impact.

- The proposed AOT and STI extensions for the reactor containment fan cooler (RCFC) system also have negligible risk impacts.

\subsection{Technical Review Conclusion}

The technical evaluation of the $11 \mathrm{TS}$ items reviewed concluded that there are negligible or minor risk impacts for a number of the proposed changes to these TS requirements. Table 6.6 summarizes the review's assessments.

The TS changes to the STP plant which have negligible or minor risk impacts consist of the following:

- For 6 systems, a 7-day AOT has negligible to minor risk impacts. For these systems, the STP submittal requested a change in AOT to 10 days from the current limit of 3 days. For one of these systems, carrying out a cross-train check of a redundant train along with the recommended AOT change will result in a minimal risk impact. Another request of AOT change from 1 hour to 12 hours also will have negligible to minor risk impacts. In 2 systems, the requested AOT changes (one request from 3 to 10 days, and another from 7 to 10 days) will not have negligible to minor risk impacts.

- Three types of STI changes were requested: from 31 days to 92 days, from 61 days to 92 days, and from 92 days to 184 days. In general, the STI changes will have negligible to minor risk impacts provided that staggered testing is used when STI is being increased to 184 days (or 6 months).

The conclusions of the technical review for each of the TS items, judged on individual risk impacts, were assessed further in terms of their total integrated impact. These conclusions (see Table 6.6) include a significant portion (but not all) of the requested changes and some additional requirements. Quantitative assessments showed that with these changes, the mean CDF will increase by $4.5 \%$, i.e., the baseline mean CDF will increase from 4.4 $\times 10^{-5} / \mathrm{yr}$ to $4.6 \times 10^{-5} / \mathrm{yr}$. As shown in Table 4.2, the impact of the STP proposed changes would have been greater than $10 \%$ incorporating the impact of changes in Essential Chilled Water System on the initiating-event frequency. 
Table 6.6 Summary of the Technical Review Conclusions for Proposed Changes to the STP TSs

\begin{tabular}{|c|c|c|}
\hline System & Proposed TS Change & $\begin{array}{l}\text { Technical Review } \\
\text { Conclusion }\end{array}$ \\
\hline $\begin{array}{l}\text { Chemical and Volume Control (CVCS) } \\
\text { (i.e., Charging Pumps) }\end{array}$ & $\begin{array}{c}\text { AOT } \\
3 \rightarrow 10 \text { days }\end{array}$ & $\underset{3 \rightarrow 7 \text { days }}{\text { AOT }}$ \\
\hline Reactor Protection (RPS) & $\underset{\mathrm{STI}}{2 \mathrm{mo} \rightarrow 3 \mathrm{mo}}$ & $\underset{\mathrm{STI}}{2 \mathrm{mo} \rightarrow 3 \mathrm{mo}}$ \\
\hline $\begin{array}{l}\text { Engineered Safeguard Features } \\
\text { Actuation (ESFAS) }\end{array}$ & $\underset{\mathrm{STI}}{2 \mathrm{mo} \rightarrow 3 \mathrm{mo}}$ & $\underset{\mathrm{STI}}{2 \mathrm{mo} \rightarrow 3 \mathrm{mo}}$ \\
\hline Accumulators (ACC) & $\begin{array}{c}\text { AOT } \\
1 \mathrm{hr} \rightarrow 12 \mathrm{hrs}\end{array}$ & $\underset{1 \mathrm{hr} \rightarrow 12 \mathrm{hr}}{\text { AOT }}$ \\
\hline Emergency Core Cooling (ECCS) & $\underset{3 \rightarrow 10 \text { days }}{\text { AOT }}$ & $\begin{array}{c}\text { AOT } \\
3 \rightarrow 7 \text { days } \\
\text { (with cross-train check) }\end{array}$ \\
\hline Residual Heat Removal (RHR) & $\begin{array}{c}\text { AOT } \\
3 \rightarrow 10 \text { days } \\
\text { STI } \\
3 \text { mo } \rightarrow 6 \text { mo }\end{array}$ & $\begin{array}{c}\text { AOT } \\
3 \rightarrow 7 \text { days } \\
\text { STI } \\
3 \text { mo } \rightarrow 6 \text { mo } \\
\text { (staggered testing) }\end{array}$ \\
\hline Containment Spray (CS) & $\begin{array}{c}\text { AOT } \\
3 \rightarrow 10 \text { days } \\
\text { STI } \\
3 \mathrm{mo} \rightarrow 6 \mathrm{mo}\end{array}$ & $\begin{array}{c}\text { AOT } \\
3 \rightarrow 7 \text { days } \\
\text { STI } \\
3 \text { mo } \rightarrow 6 \text { mo } \\
\text { (staggered testing) }\end{array}$ \\
\hline $\begin{array}{l}\text { Reactor Containment Fan Coolers } \\
\text { (RCFC) }\end{array}$ & $\begin{array}{c}\text { AOT } \\
3 \rightarrow 10 \text { days } \\
\text { STI } \\
1 \mathrm{mo} \rightarrow 3 \mathrm{mo}\end{array}$ & $\begin{array}{c}\text { AOT } \\
3 \rightarrow 7 \text { days } \\
\text { STI } \\
1 \mathrm{mo} \rightarrow 3 \mathrm{mo}\end{array}$ \\
\hline Component Cooling Water (CCW) & $\begin{array}{c}\text { AOT } \\
3 \rightarrow 10 \text { days }\end{array}$ & $\underset{3 \rightarrow 7 \text { days }}{\text { AOT }}$ \\
\hline Control Room HVAC & $\begin{array}{c}\text { AOT } \\
7 \rightarrow 10 \text { days } \\
(1 \mathrm{st} \text { Train) } \\
24 \rightarrow 72 \text { hrs } \\
\text { (2nd Train) } \\
\text { STI } \\
1 \text { mo } \rightarrow 3 \text { mo }\end{array}$ & $\begin{array}{c}\text { AOT } \\
7 \text { days } \\
(1 \mathrm{st} \text { Train) } \\
24 \rightarrow 72 \text { hrs } \\
\text { (2nd Train) } \\
\text { STI } \\
1 \mathrm{mo} \rightarrow 3 \text { mo }\end{array}$ \\
\hline Essential Chilled Water (ECW) & $\begin{array}{c}\text { AOT } \\
3 \rightarrow 10 \text { days }\end{array}$ & $\begin{array}{l}\text { AOT } \\
3 \text { days }\end{array}$ \\
\hline
\end{tabular}




\section{SUMMARY}

This report presents an approach to reviewing PSA-based analyses of changes to Technical Specifications (TSs) of nuclear power plants. The review of PSA-based submittal for changes in the TSs requires that relevant safety issues that arise from the proposed modifications are addressed. We discuss an approach to reviewing a PSAbased TS submittal, using the review of South Texas Project (STP) submittal to change the TS of its nuclear generating facilities which we conducted recently.

The review approach, details the following aspects:

1. The objectives of review of a PSA-based TS submittal, and the differences from a PSA review,

2. The methodology for reviewing a PSA-based TS submittal,

3. The review steps to be followed, and

4. The check-lists of items that can be used by the reviewers.

The review approach is discussed in sufficient detail to provide guidance to reviewers for completing a technical review of such PSA-based TS submittals. 


\section{REFERENCES}

1. P.K. Samanta, I.S. Kim, T. Mankamo, and W.E. Vesely, "Handbook of Methods for Risk-Based Analyses of Technical Specifications," NUREG/CR-6141, BNL-NUREG-52398, Brookhaven National Laboratory, December 1994.

2. P. K. Samanta, S. M. Wong, and J. Carbonaro, "Evaluation of Risk Associated with AOT and STI Requirements at the ANO-1 Nuclear Power Plant," NUREG/CR-5200, BNL-NUREG-52024, Brookhaven National Laboratory, August 1988.

3. W. E. Vesely, "Evaluation of Allowed Outage Times from a Risk and Reliability Standpoint," NUREG/CR-5425, BNL-NUREG-52213, Brookhaven National Laboratory, August 1989.

4. P. K. Samanta, W. E. Vesely, I. S. Kim, "Study of Operational Risk-Based Configuration Control," NUREG/CR-5641, BNL-NUREG-52261, Brookhaven National Laboratory, August 1991.

5. D. Wagner, W. E. Vesely, and L. A. Minton, "Risk-Based Evaluation of Technical Specifications," EPRI-NP-4317, Electric Power Research Institute, March 1987.

6. T. Mankamo, P. Samanta, and T. Tjader, "Risk-Based Optimization of Technical Specifications for Operation of Nuclear Power Plants," IAEA-TECDOC-729, International Atomic Energy Agency, Vienna, Austria, December 1993.

7. I. S. Kim, S. Martorell, W. E. Vesely, and P. K. Samanta, "Quantitative Evaluation of Surveillance Test Intervals Including Test Caused Risks," NUREG/CR-5775, BNL-NUREG-52296, Brookhaven National Laboratory, February 1992.

8. P.K. Samanta, G. Martinez-Guridi, W.E. Vesely, "Technical Evaluation of South Texas Project (STP) Analysis for Technical Specification Modification," BNL Technical Report, L2591 1-11-94, Brookhaven National Laboratory, January 1994.

9. NUREG-1489, "A Review of NRC Staff Use of Probabilistic Risk Assessment," U.S. Nuclear Regulatory Commission, 1994.

10. I. Kim and P. Samanta, "Risk-Based Analyses of ABWR Technical Specifications," BNL Technical Report, L1692 Task 12, Brookhaven National Laboratory, July 1994.

11. Houston Lighting \& Power, "Proposed Amendment to the Unit 1 and Unit 2 Technical Specifications Based on Probabilistic Analyses," Document ST-HL-AE-3283, February 1, 1990.

12. Houston Lighting \& Power, "Response to Request for Additional Information Regarding Review of the Proposed Changes to the South Texas Project Technical Specifications," Document ST-HL-AE-4261, November 11, 1992.

13. Houston Lighting and Power, "Response to Request for Additional Information Regarding Review of the Proposed Changes to the South Texas Project Technical Specifications, " Document ST-HL-AE-4544, August 16, 1993.

14. Letter from Lawrence E. Kokajko to William Cottle, "Request for Additional Information Regarding Review of the Proposed Changes to the South Texas Project Technical Specifications," U.S. Nuclear Regulatory Commission, May 19, 1993. 
15. Houston Lighting \& Power, "Additional Information in Support of the Proposed Changes to the South Texas Project Technical Specifications, " Document ST-HL-AE-4620, November 5, 1993.

16. Pickard, Lowe and Garrick, Inc., "South Texas Project Probabilistic Safety Assessment, " PLG-0675, May 1989.

17. Houston Lighting \& Power Company, "South Texas Project Electric Generating Station Level 2 Probabilistic Safety Assessment and Individual Plant Examination, " Document ST-HL-AE-4193, August 1992.

18. Wheeler, T. A., Darby, J. L., Lambright, J. A., "A Review of the South Texas Project Probabilistic Safety Analysis for Accident Frequency Estimates and Containment Binning, "NUREG/CR-5606, Sandia National Laboratory, August 1991.

19. Pickard, Lowe and Garrick, Inc., "RISKMAN 3 Computer Code User Manual, "Revision O/VM, PLG0644, PLG Inc., Newport Beach, CA, August 1988.

20. U.S. Nuclear Regulatory Commission, "Severe Accident Risks: An Assessment of Five U.S. Nuclear Power Plants," NUREG-1150, January 1991.

21. P. Samanta, T. Ginzburg, and W. Vesely, "Consideration of Test Strategy in Defining Surveillance Test Intervals, " BNL Technical Report A-3859, Brookhaven National Laboratory, October 1988. 
Reviewing PSA-Based Analyses to Modify Technical Specifications at Nuclear Power Plants

BNL-NUREG-52428

P. K. Samanta, G. Martinez-Guridi, W. E. Vesely*

\begin{tabular}{|l|l|}
\hline 3. \\
\hline MONTH REPORT PUBLISHED \\
DecembEr & YEAR \\
\hline $\begin{array}{l}\text { 4. FINOR GRANT NUMBER } \\
\text { L2591 }\end{array}$ \\
$\begin{array}{l}\text { 6. TYPE OF REPORT } \\
\text { Technical }\end{array}$ \\
$\begin{array}{l}\text { 7. PERIOD COVERED (Inclusive Dates) } \\
\text { March } 1994- \\
\text { January } 1995\end{array}$
\end{tabular}

8. PERFORMING ORGANIZATION - NAME AND ADDRESS (If NRC, provide Division, Office or Region, U.S. Nuclear Regulatory Commission, and mailling address; if contractor, provide name and mailing address.

Brookhaven National Laboratory

* Science Applications Internal Corporation

Upton, NY 11973-5000

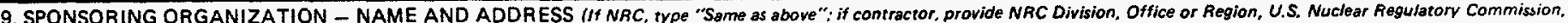
and mailing address.)

Division of Systems Technology

Office of Nuclear Regulatory Research

U.S. Nuclear Regulatory Commission

Washington, DC 20555-0001

10. SUPPLEMENTARY NOTES

E. Chelliah, NRC Project Manager

11. ABSTRACT (200 words or less)

Changes to Technical Specifications (TSs) at nuclear power plants (NPPs)

require review and approval by the United States Nuclear Regulatory Commission

(USNRC). Currently, many requests for changes to TSs use analyses that are

based on a plant's probabilistic safety assessment (PSA). This report

presents an approach to reviewing such PSA-based submittals for changes to

TSs. We discuss the basic objectives of reviewing a PSA-based submittal to modify NPP TSs; the methodology of reviewing a TS submitta1, and the differing roles of a PSA review, a PSA Computer Code review, and a review of a TS submittal. To illustrate this approach, we discuss our review of changes to allowed outage time (AOT) and surveillance test interval (STI) in the TS for the South Texas Project Nuclear Generating Station. Based on this experience gained, a check-7ist of items is given for future reviewers; it can be used to verify that the submittal contains sufficient information, and also that the review has addressed the relevant issues. Finally, recommended steps in the review process and the expected findings of each step are discussed.

Nuclear Power Plants - Probabilistic Estimation, Nuclear Power Plants - specifications, Reactor Operation - Risk Assessment, BNL, Outages, Reactor Shutdown, Reactor Components, Reactor Operation, Reliability, Standardization, South Texas Project-1 Reactor, USNRC

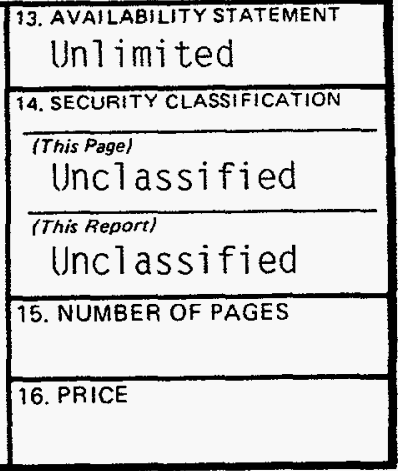

